\title{
Attribution of 2012 extreme climate events: does air-sea interaction matter?
}

\author{
Buwen Dong $^{1}$ (I) $\cdot$ Rowan T. Sutton $^{1} \cdot$ Len Shaffrey $^{1} \cdot$ Laura J. Wilcox $^{1}$
}

Received: 22 February 2020 / Accepted: 30 May 2020 / Published online: 4 June 2020

(c) The Author(s) 2020

\begin{abstract}
In 2012, extreme anomalous climate conditions occurred around the globe. Large areas of North America experienced an anomalously hot summer, with large precipitation deficits inducing severe drought. Over Europe, the summer of 2012 was marked by strong precipitation anomalies with the UK experiencing its wettest summer since 1912 while Spain suffered severe drought. What caused these extreme climate conditions in various regions in 2012? This study compares attribution conclusions for 2012 climate anomalies relative to a baseline period (1964-1981) based on two sets of parallel experiments with different model configurations (with coupling to an ocean mixed layer model or with prescribed sea surface temperatures) to assess whether attribution conclusions concerning the climate anomalies in 2012 are sensitive to the representation of air-sea interaction. Modelling results indicate that attribution conclusions for large scale surface air temperature (SAT) changes in both boreal winter and summer are generally robust and not very sensitive to air-sea interaction. This is especially true over southern Europe, Eurasia, North America, South America, and North Africa. Some other responses also appear to be insensitive to air-sea interaction: for example, forced increases in precipitation over northern Europe and Sahel, and reduced precipitation over North America and the Amazon in boreal summer. However, the attribution of circulation and precipitation changes for some other regions exhibits a sensitivity to air-sea interaction. Results from the experiments including coupling to an ocean mixed layer model show a positive NAO-like circulation response in the Atlantic sector in boreal winter and weak changes in the East Asian summer monsoon and precipitation over East Asia. With prescribed sea surface temperatures, some different responses arise over these two regions. Comparison with observed changes indicates that the coupled simulations generally agree better with observations, demonstrating that attribution methods based on atmospheric general circulation models have limitations and may lead to erroneous attribution conclusions for regional anomalies in circulation, precipitation and surface air temperature.
\end{abstract}

Keywords Attribution · Climate extreme $\cdot$ Anthropogenic forcing $\cdot$ Air-sea interaction $\cdot$ Surface warming $\cdot$ Circulation . Precipitation

\section{Introduction}

Weather and climate extreme events can have devastating impacts on human society, the economy, and the infrastructure. Attribution of these extreme events is one of pressing challenges for the climate science community (WCRP 2013) and is a fundamental step in developing robust climate predictions and guiding climate adaptation strategies. While a

Buwen Dong

buwen.dong@ncas.ac.uk

1 Department of Meteorology, National Centre for Atmospheric Science, University of Reading, Reading RG6 6BB, UK specific weather or climate extreme event cannot be solely attributed to a single cause, it is still possible to estimate how certain factors, such as the effects of anthropogenic forcing, may have affected the risk of occurrence and/or contributed to the intensity of specific events (Trenberth et al. 2015; NAS 2016; Shepherd 2016; Stott et al. 2016; Otto 2017). Conclusions on weather and climate event attribution could be influenced by the way the event is framed, and the suitability of method and model used (NAS 2016; Shepherd 2016; Stott et al. 2016; Uhe et al. 2016; Otto 2017; Risser et al. 2017; Fischer et al. 2018; Otto et al. 2018, Stone et al. 2018). The science seeking to understand the underlying factors leading to extreme weather and climate events has received growing attention over the past few years. 
In particular, attention has been devoted to estimating the separate contributions of anthropogenic forcings through dynamic and thermodynamic effects on extreme weather and climate events (Vautard et al. 2016; Cheng et al. 2018; Sánchez-Benítez et al 2018).

2012 was characterized by anomalous climate conditions around the globe (Blunden and Arndt 2013; Peterson et al. 2013). In boreal winter, Central Europe experienced a cold spell associated with extreme blocking (de Vries et al. 2013). Meanwhile, the Iberian Peninsula had its driest January-February since 1951 which was associated with a positive North Atlantic Oscillation (NAO) (Trigo et al. 2013). There were also anomalous climate events in austral summer including increased precipitation over southeast Australia (King et al. 2013), intense rain in the Amazon, and record drought over northeast Brazil (Blunden and Arndt 2013; Marengo et al. 2013). In boreal summer, large areas of North America experienced an anomalously hot summer with anomalous precipitation deficits inducing severe drought (Diffenbaugh and Scherer 2013; Hoerling et al. 2013; Rupp et al. 2013, 2017). Summer seasonal mean climate anomalies over Europe were characterized by wet conditions over northern Europe and dry and hot conditions over southern Europe, associated with a negative Summer North Atlantic Oscillation (SNAO) (e.g., Folland et al. 2009; Dong et al. 2013). Area averaged indices show that northern Europe experienced the second wettest year and southern Europe the third driest year since 1951 (Dong et al. 2013; Yiou and Cattiaux 2013; Wilcox et al. 2018). Meanwhile, the Sahel experienced anomalously wet conditions (Cornforth 2013; Parker et al. 2017) and North China experienced severe flooding (Zhou et al. 2013).

Previous attribution studies found there has been a significant anthropogenic impact on increasing risk of hot summers such as 2012 in southern Europe (Wilcox et al. 2018) and North America (Diffenbaugh and Scherer 2013). However, there is a more limited role for an anthropogenic contribution to precipitation anomalies in summer 2012 over China (Zhou et al. 2013), over North America (Hoerling et al. 2013; Rupp et al. 2017), over Europe (Wilcox et al. 2018), and over southeast Australia in austral summer (King et al. 2013). In addition, there have been mixed conclusions regarding the influence of anthropogenic forcing on Sahelian precipitation based on different model ensembles (Parker et al. 2017).

Most of the above attribution studies on extreme events in 2012 have used atmospheric general circulation models (AGCMs) forced by prescribed sea surface temperatures (SSTs), with and without anthropogenic influences. A potential limitation of these studies is the lack of explicit atmosphere-ocean coupling. This limitation may be important since the lack of air-sea coupling in AGCMs causes an inconsistency in surface energy fluxes and can limit a model's ability to accurately simulate natural climate variability (e.g., Barsugli and Battisti 1998; Wang et al. 2005; He and Soden 2016). In addition, studies have shown that air-sea coupling improves the simulation of mean climate in the tropics, improves the representation of tropical precipitation extremes (Hirons et al. 2018), and improves monsoon prediction (e.g., Hendon et al. 2012; Zhu and Shukla 2013). Dong et al. (2017b) demonstrated that attribution conclusions for forced decadal surface air temperature changes derived from AGCM experiments are generally robust and not very sensitive to air-sea coupling. However, externally forced decadal changes in seasonal mean precipitation and circulation in some regions show large sensitivity to air-sea coupling, notably in the summer monsoons over East Asia and Australia. Fischer et al. (2018) demonstrated that changes in the probability of temperature extremes over the tropics and Australia in response to global warming could be overestimated using prescribed SSTs than a fully coupled model configuration, suggesting an important role of air-sea interaction for attribution conclusions concerning temperature extremes over the tropics.

The evidence that air-sea coupling is important for the simulation of climate, climate variability, and the attribution of externally forced decadal changes and temperature extremes motivates us to investigate the implications for attribution studies of some events in a particular year. In this study, climate events in 2012 are investigated relative to the baseline climatological period (1964-1981). In particular, we seek to explore whether attribution conclusions obtained from AGCM experiments are robust for these events. Our approach is to compare attribution conclusions for 2012 events derived from experiments with a coupled climate model with conclusions derived from parallel experiments with the same AGCM forced by SSTs taken from the coupled model experiments. The AGCM and coupled model simulations are forced with consistent boundary conditions and radiative forcing and thereby allow us to assess the importance of air-sea coupling for attribution conclusions for these particular events. The structure of the paper is as follows: in Sect. 2, the observational data, model, and experiments used are briefly described; The main features of seasonal changes in surface air temperature, circulation and precipitation in 2012 are documented in Sect. 3. Section 4 presents the global responses of surface air temperature, circulation and precipitation to changes in anthropogenic forcing in 2012 in the coupled and uncoupled model simulations; An assessment of whether coupling improves the comparison between the model simulations and observations, and the effect this has on attribution statements are in Sect. 5; and finally, conclusions are given in Sect. 6 . 


\section{Observational data, model, and model experiment design}

\subsection{Observational data}

Observations used are the CRU TS3.21 monthly data set (Harris et al. 2014), the University of Delaware (UD) air temperature and precipitation data set (UDel_AirT_Precip) version 4.01 (Willmott and Matsuura 2001), Global Historical Climatology Network (GHCN) gridded V3 SAT data set (Jones and Moberg 2003), Global Precipitation Climatology Centre (GPCC) V7 precipitation data set (Schneider et al. 2014), GPCP v2.2 precipitation data set (Adler et al. 2003). The monthly sea surface temperature data set is from HadISST (Rayner et al. 2003), monthly sea level pressure data set is from HadSLP2r (Allan and Ansell 2006), and $850 \mathrm{hPa}$ wind distribution is from the NCEP reanalysis (Kalnay et al. 1996).

\subsection{The MetUM-GA6 and MetUM-GOML2 models}

The atmospheric component of the climate model used in this study is the Met Office Unified Model (MetUM) version 6 of the Global Atmosphere (GA6) and JULES Global Land (GL6) configuration (Walters et al. 2017). The current dynamical core of the MetUM (ENDGame; Wood et al. 2014) solves the non-hydrostatic, fully compressible, deepatmosphere equations of motion using a semi-implicit semiLagrangian scheme on a regular latitude/longitude grid, with an explicit diffusion scheme. In this study, model is run at N96 horizontal resolution with $1.25^{\circ} \times 1.875^{\circ}$ grid in latitude and longitude with 85 vertical levels, corresponding to a resolution of about $100 \mathrm{~m}$ in the lower troposphere, decreasing to more than $5 \mathrm{~km}$ in the thermosphere with a lid at $85 \mathrm{~km}(0.004 \mathrm{hPa})$.

The ocean-atmosphere coupled modelling framework, MetUM-GOML2, comprises MetUM-GA6 coupled to the Multi-Column $K$ Profile Parameterization (MC-KPP) mixed-layer ocean model via the Ocean Atmosphere Sea Ice Soil (OASIS) coupler ( Valcke et al. 2003) with a three-hour coupling frequency. The latitudinal domain of the air-sea coupling is limited by the maximum extent of a seasonally varying sea ice climatology (Fig. 2 of Hirons et al. 2015). In the uncoupled region of MetUM-GOML2, the atmosphere is forced by the repeating mean annual cycle of SST and sea ice extent (SIE) of 2012 from the Met Office HadISST data set (Rayner et al. 2003). MC-KPP is run as a twodimensional matrix of one-dimensional water columns, with one column below each AGCM grid point that is wholly or partially ocean. Each MC-KPP column has a depth of $1000 \mathrm{~m}$ and is comprised of 100 levels. This allows very high resolution (approximately one metre) to be used in the upper ocean. Vertical mixing in MC-KPP is parameterised using the KPP scheme of Large et al. (1994). Since MC-KPP simulates only vertical mixing and does not include ocean dynamics, climatological seasonal cycles of depth-varying temperature and salinity corrections are prescribed to represent the mean ocean advection and account for biases in atmospheric surface fluxes. The computation of these corrections is described below. More detailed documentation of an earlier version of coupled model (MetUM-GOLM1) was given in Hirons et al. (2015).

\subsection{Experiments with coupled and atmospheric only model}

A 12 year relaxation experiment using MetUM-GOML2, with 2012 greenhouse gases (GHGs) and anthropogenic aerosol (AA) forcings, in which the Multi-Column K Profile Parameterization (MC-KPP) profiles of ocean temperature and salinity are constrained to 2012 (January to December) from the Met Office ocean analysis (Smith and Murphy 2007) with a relaxation timescale of 15 days (Experiment R0, Table 1), is used to provide temperature and salinity corrections for the coupled model experiments. The daily mean seasonal cycle of temperature and salinity corrections from the relaxation experiment are diagnosed from

Table 1 The experimental design for 2012 case study

\begin{tabular}{llll}
\hline Experiment & Ocean & Radiative forcing (RF) \\
\hline R0 & Relaxation run & $\begin{array}{c}\text { Relaxation to 2012 ocean temperature (T), } \\
\text { salinity (S) to diagnose climatological T, S } \\
\text { tendencies }\end{array}$ & $\begin{array}{c}2012 \text { GHGs and appropriate AA emissions } \\
\text { (Lamarque et al. 2011) }\end{array}$ \\
C2012 & Coupled 2012 run & Clim T, S tendencies imposed from R0 & 2012 GHGs and appropriate AA emissions \\
Cclim & Coupled Clim (1964-1981) run & Clim T, S tendencies imposed from R0 & Time mean 1964-1981 GHGs and time mean \\
& & & $1970-1981$ AA emissions (Lamarque et al. \\
A2012 & AGCM 2012 run & Daily SST from C2012 & RF as for C2012 \\
Aclim & AGCM Clim (1964-1981) run & Daily C2012 SST - Clim (C2012-Cclim) daily & RF as for Cclim \\
& & SST &
\end{tabular}


the last 10 years of the R0 simulation and imposed in the free-running coupled C2012 and Cclim (which uses the time mean anthropogenic forcings averaged over baseline period 1964-1981) simulations with no interactive relaxation. We chose 1964-1981 as the baseline period to avoid volcanic impacts (there were no major eruptions during this period), and the rapid warming that occurred after the 1980s (Bindoff et al. 2013; Wild 2016). Two equivalent atmosphere-only experiments (A2012 and Aclim) were also performed. These experiments are forced by the daily SSTs from C2012 experiment and by daily SSTs from C2012, but with the influence of the change in GHGs and AA forcings on climatological SSTs (C2012-Cclim) removed (Table 1). Relative to the baseline 1964-1981 period, there were significant increases in GHGs concentrations in 2012 with $\mathrm{CO}_{2}, \mathrm{CH}_{4}$, and $\mathrm{N}_{2} \mathrm{O}$ increased by $20 \%, 27 \%$, and $9 \%$, respectively (WMO 2014). There were also significant changes in anthropogenic aerosol and precursor emissions (Lamarque et al 2010, 2011), including sulphur dioxide (Fig. 1), soot, fossil fuel organic carbon (not shown), with reduced emissions over Europe and North America and increased emissions from Asia.

The four simulations were run for 45 years, with the 2012 sea ice extent from HadISST (Rayner et al. 2003) being used in each case. The last 40 years are used for the analysis. The impact of external forcing changes within the coupled framework will be diagnosed by comparing results between experiments C2012 and Cclim (C2012-Cclim). The impact of external forcing changes within the uncoupled framework will be diagnosed by comparing results between experiments A2012 and Aclim (A2012-Aclim). Assuming the diurnal cycle of SSTs is not important for the climate response, the differences in response between the coupled and AGCM simulations are mainly due to the lack of coupling with an underlying ocean. Responses in both the coupled and uncoupled frameworks can be compared to observations to demonstrate whether the air-sea

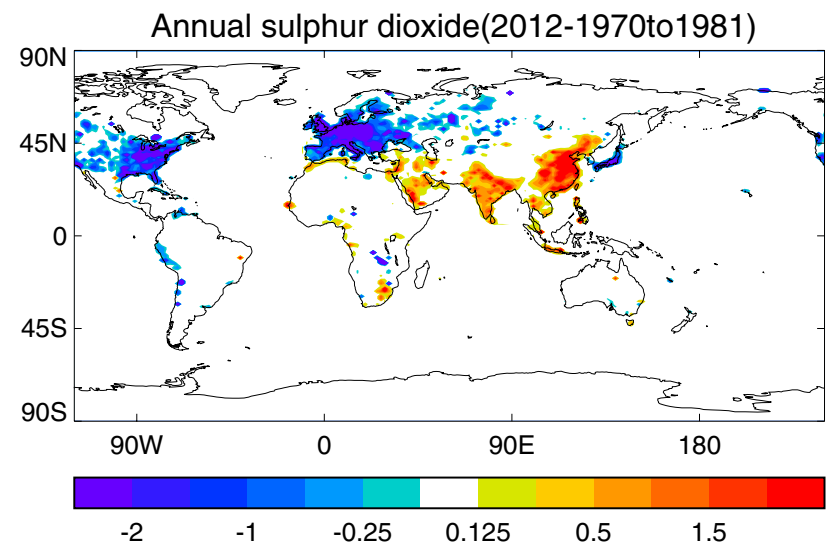

Fig. 1 Differences in annual mean sulfur dioxide emission rate $\left(\mathrm{g} \mathrm{m}^{-2}\right.$ year ${ }^{-1}$ ) between 2012 and the baseline period 1970-1981 coupling improves the agreement with the observed differences between 2012 and the 1964-1981 baseline period. The analyses in this study focus on boreal winter (January-March, JFM) and summer (June-August, JJA).

\subsection{Model simulated climate of $\mathbf{2 0 1 2}$}

Figure 2a and $\mathrm{b}$ show SST biases for the C2012 experiment relative to 2012 in HadISST in boreal winter and summer. By prescribing the temperature and salinity corrections, climatological mean SST biases in both boreal winter and summer in the MetUM-GOML2 model are much smaller (typically between -0.5 and $0.5^{\circ} \mathrm{C}$ ) than those in CMIP5 models (Wang et al. 2014; Hirons et al. 2015), and are similar to the biases of the MetUM-GOML1 simulation for present day climate shown in Dong et al. (2017b).

Figure $2 \mathrm{c}$ and $\mathrm{d}$ show the seasonal JFM and JJA precipitation climatologies from the A2012 experiment, while Fig. 2e and $f$ show the biases of precipitation in A2012 relative to GPCP. In comparison with observations, the simulated precipitation from the A2012 experiment is overestimated over the northwest Pacific, Maritime Continent (MC), Indian Ocean and East Asia and underestimated over the Amazon and central Africa in JFM. In JJA, the A2012 experiment exhibits wet biases over the equatorial Indian Ocean (EIO) and western tropical Pacific and dry biases over the Indian subcontinent, MC islands, East China, and Korean Peninsula (Fig. 2f). These tropical rainfall biases are long-standing errors in the MetUM (e.g., Ringer et al. 2006; Walters et al. 2017), and were also present in other CMIP3 models and not much improved in CMIP5 models (Sperber et al. 2013). One other large bias is the weak precipitation over the Sahel associated with the West African summer monsoon in boreal summer (Fig. 2f). This dry bias might be related to cold bias in simulated SST over the northern subtropical Atlantic (Fig. 2b), resulting a cross-equatorial SST gradient (e.g., Martin et al. 2014).

Relative to A2012, the C2012 experiment exhibits a very similar spatial distribution of precipitation over global land in JFM (Fig. 2g). Air-sea coupling reduces dry biases over the MC islands shown in the atmospheric model simulation. In JJA, precipitation biases over the EIO, MC islands, and East China are improved in C2012 relative to A2012, but the dry bias over the Indian subcontinent gets worse (Fig. 2h). These results indicate the importance of air-sea coupling for the simulation of the precipitation climatology over these regions (e.g., Hendon et al. 2012; Zhu and Shukla 2013). However, coupling clearly does not eliminate the biases in the atmospheric model simulations. 
(a) JFM mean SST bias for 2012

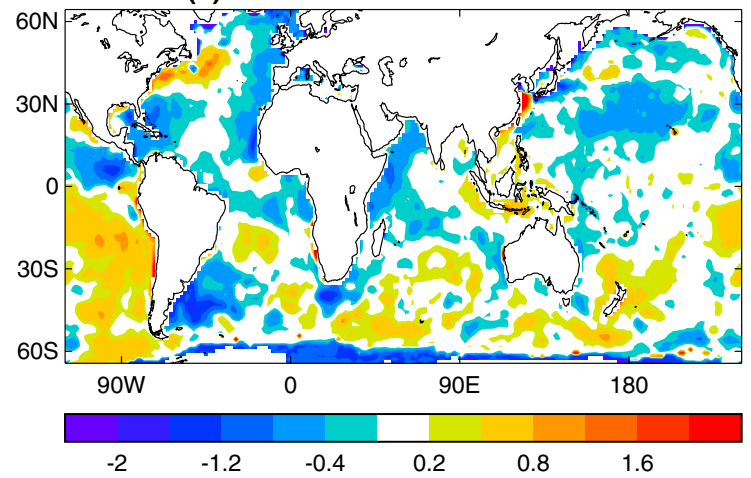

(c) JFM Precipitation (Uncoupled)

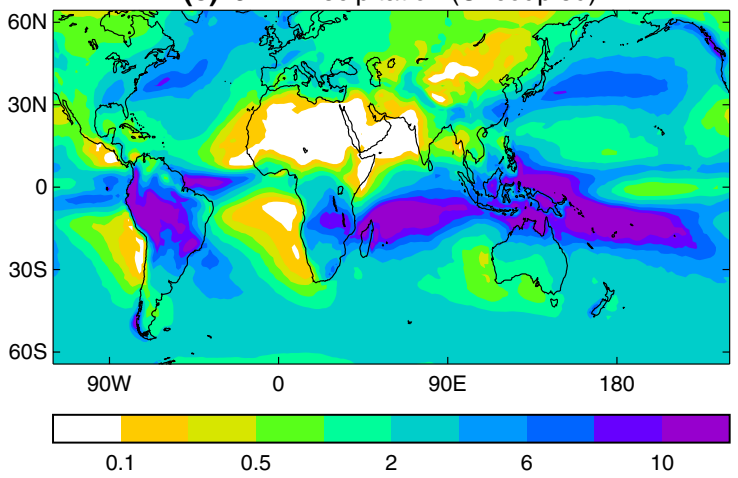

(e) JFM precipitation bias (Uncoupled)

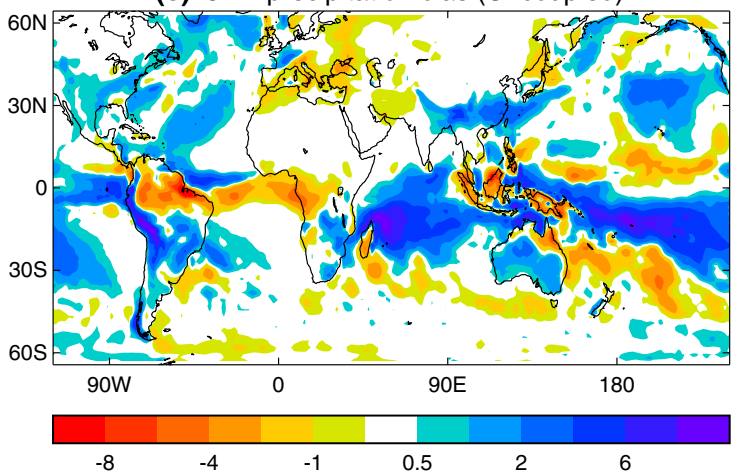

(g) JFM Precipitation change (Coupled-Uncoupled)

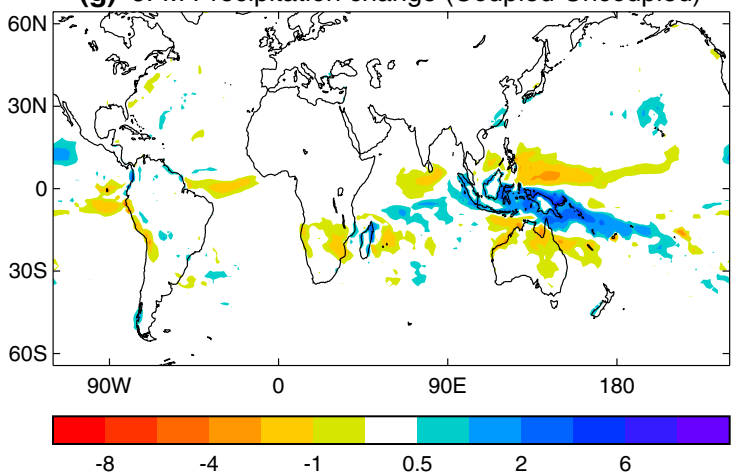

Fig. 2 Sea surface temperature $\left({ }^{\circ} \mathrm{C}\right)$ bias in the coupled simulation in 2012 (C2012). a For JFM and b for JJA relative to HadISST (Rayner et al. 2003). Precipitation $\left(\mathrm{mm} \mathrm{day}^{-1}\right)$ in the uncoupled simulation (A2012) for JFM (c) and for JJA (d). e JFM and f JJA pre- (b) JJA mean SST bias for 2012

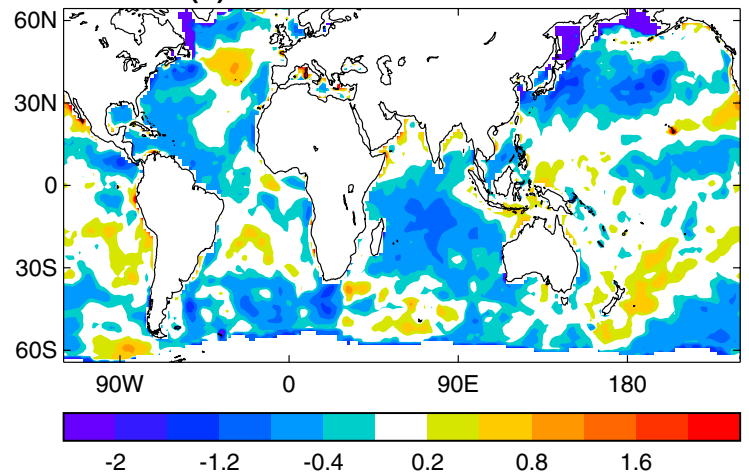

(d) JJA Precipitation (Uncoupled)

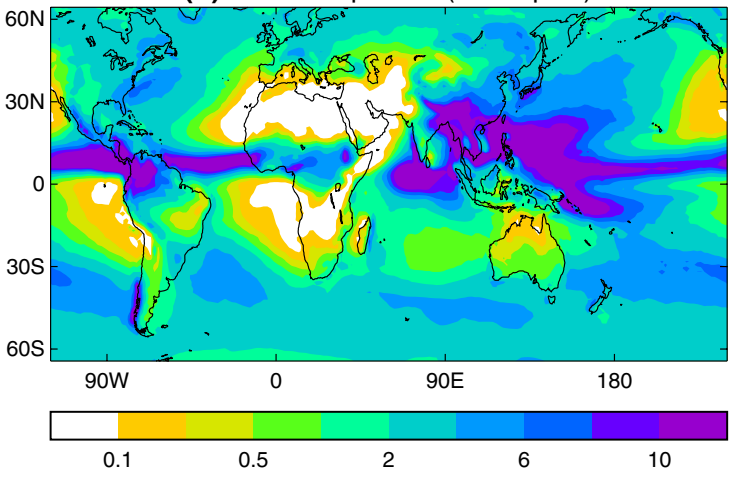

(f) JJA precipitation bias (Uncoupled)

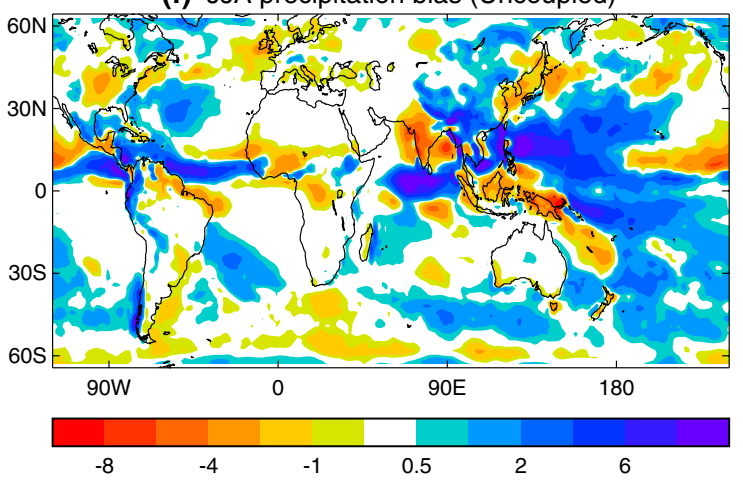

(h) JJA Precipitation change (Coupled-Uncoupled)

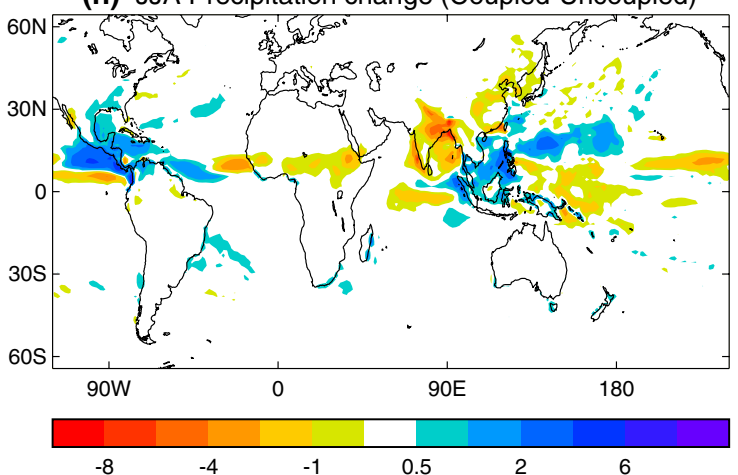

cipitation bias in the uncoupled simulation (A2012) relative to GPCP v2.2 (Adler et al. 2003). g JFM and h JJA precipitation differences between the coupled and uncoupled simulations (C2012-A2012) 


\section{Observed surface air temperature and precipitation anomalies in 2012}

Illustrated in Fig. 3 are surface air temperature (SAT) and precipitation anomalies in 2012 for JFM and JJA relative to the baseline period climatology over 1964-1981 based on the CRU TS3.21 monthly data set (Harris et al. 2014). Time series of the area averaged SAT and precipitation anomalies for various regions, where observations showed extreme seasonal mean anomalies (either in SAT or precipitation) in 2012, are shown in Fig. 4.

(a) JFM Obs. SAT change 2012-(1964to1981)

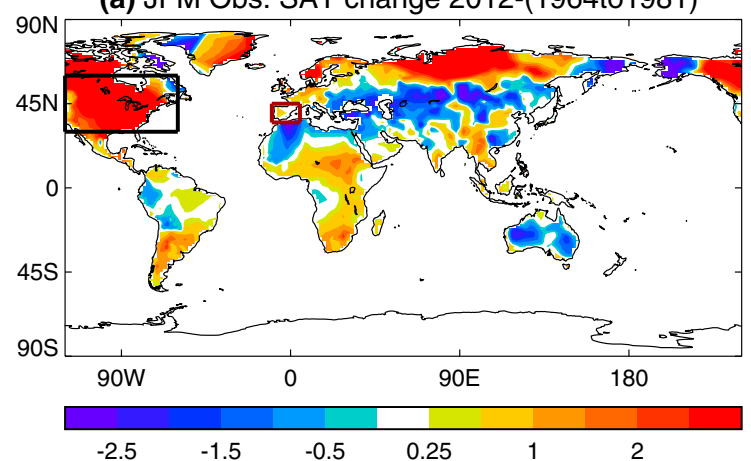

(c) JFM Obs. Pr. change 2012-(1964to1981)

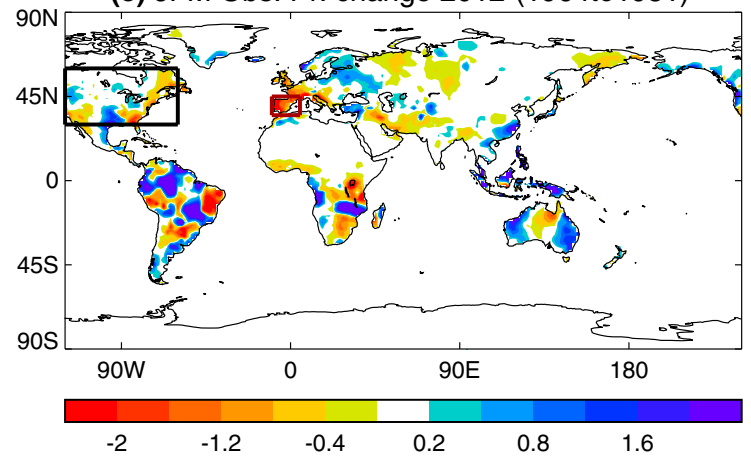

(e) JFM Obs. SLP change 2012-(1964to1981)

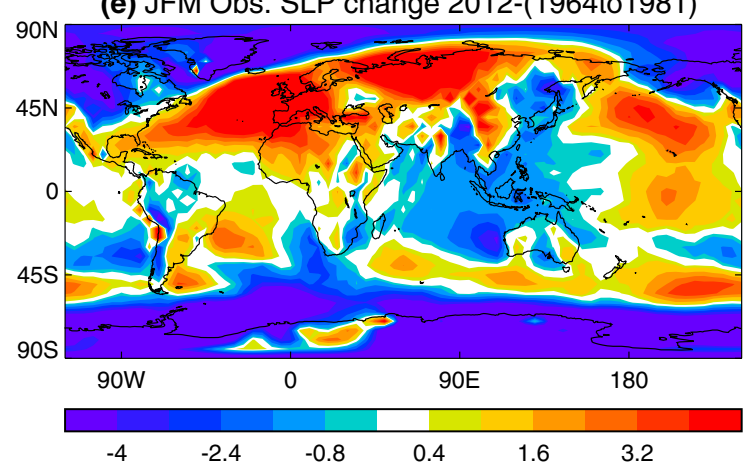

Fig. 3 a and b Surface air temperature $\left({ }^{\circ} \mathrm{C}\right)$, c and $\mathbf{d}$ precipitation $\left(\mathrm{mm} \mathrm{day}^{-1}\right)$, and e and f SLP (hPa) difference between 2012 and climatological period (1964-1981) for JFM (left panel) and JJA (right
Relative to the baseline climatology, the most prominent features in boreal winter (JFM) 2012 are warming anomalies above $3.0^{\circ} \mathrm{C}$ over North America, and a dipole pattern of SAT anomalies over the Eurasian continent with anomalous warming over high latitudes and anomalous cooling over mid-latitudes (Fig. 3a), associated with positive SLP anomalies over the North Atlantic across the U.K. and into central Eurasia (Fig. 3e). These circulation anomalies project to a positive phase of NAO (Trigo et al. 2013). Corresponding changes in precipitation are dry anomalies over the Iberian Peninsula (e.g., de Vries et al. 2013) and wet anomalies over central and eastern Europe (Fig. 3c). Time series of area

(b) JJA Obs. SAT change 2012-(1964to1981)

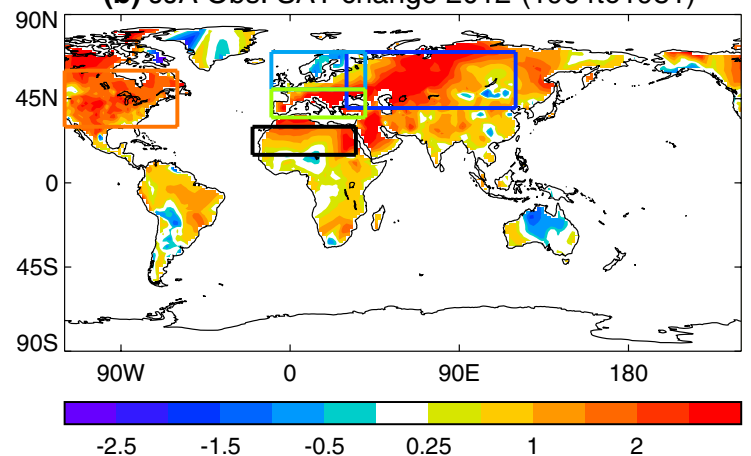

(d) JJA Obs. Pr. change 2012-(1964to1981)

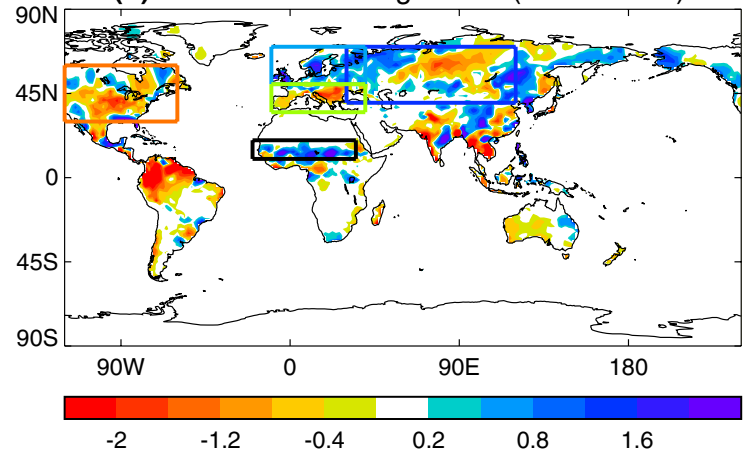

(f) JJA Obs. SLP change 2012-(1964to1981)

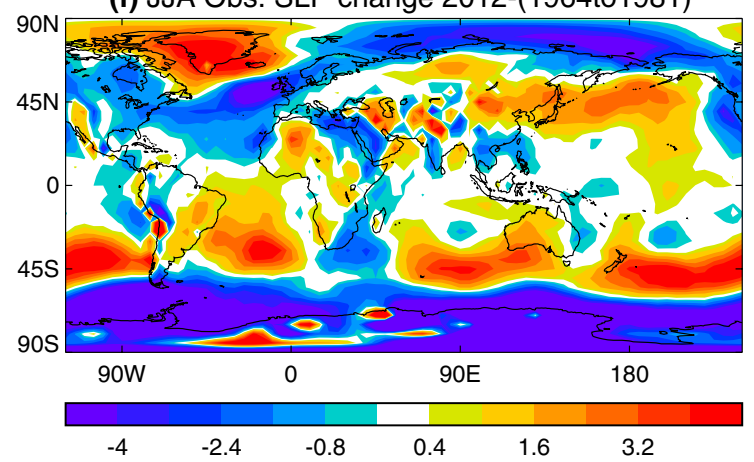

panel) based on CRUTS3.21 (Harris et al. 2014). Coloured boxes highlight regions for which time series are shown in Fig. 4 
(a) Area averaged indices over North America in JFM

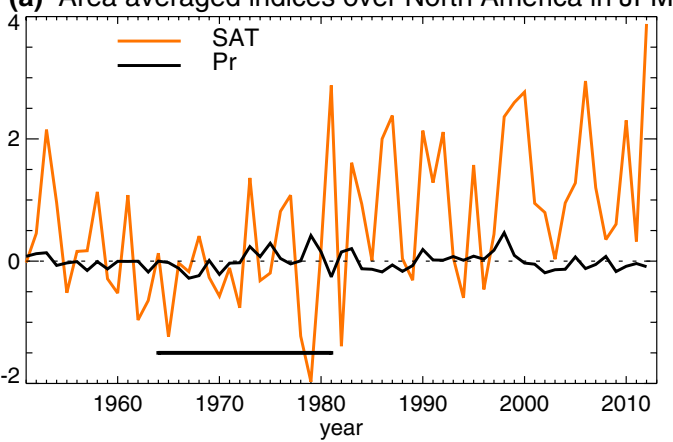

(c) Area averaged indices over NH in JJA

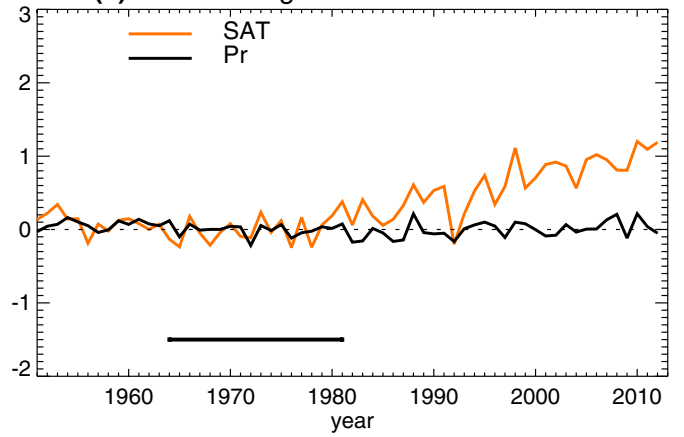

(e) Area averaged indices over North Europe in JJA

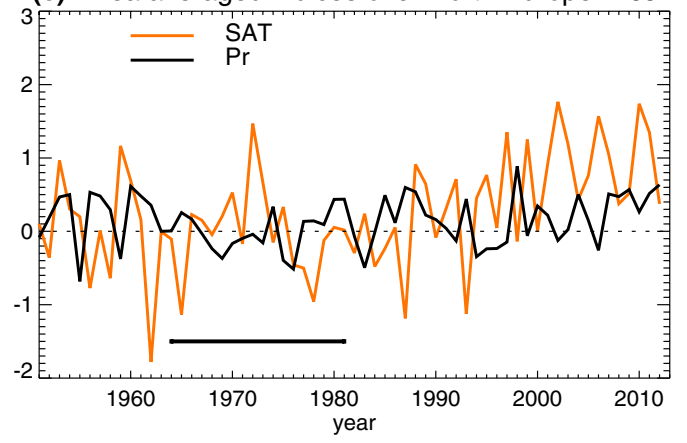

(g) Area averaged indices over North America in JJA

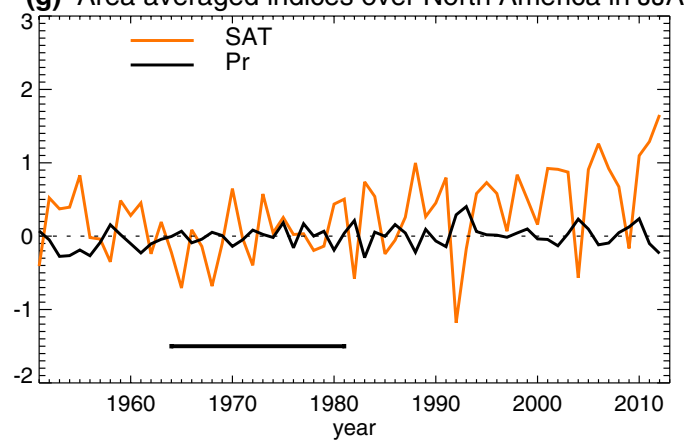

Fig. 4 Time series of area averaged SAT and precipitation anomalies from CRUTS3.21 over land in the various regions highlighted in Fig. 3. The unit is in ${ }^{\circ} \mathrm{C}$ for temperature and in $\mathrm{mm} \mathrm{day}^{-1}$ for precipitation (Pr). These regions are a North America $\left(120^{\circ}-60^{\circ} \mathrm{W}\right.$, $\left.30^{\circ}-60^{\circ} \mathrm{N}\right)$, b Iberian Peninsula $\left(10^{\circ} \mathrm{W}-5^{\circ} \mathrm{E}, 35^{\circ}-45^{\circ} \mathrm{N}\right)$ in JFM, c Northern Hemisphere, d Eurasia $\left(30^{\circ}-120^{\circ}\right.$ E, $\left.40^{\circ}-70^{\circ} \mathrm{N}\right)$, e northern (b) Area averaged indices over Iberian Peninsula in JFM

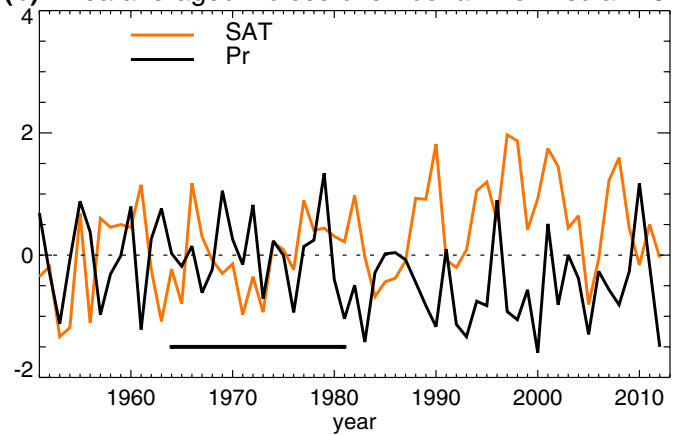

(d) Area averaged indices over Eurasia in JJA

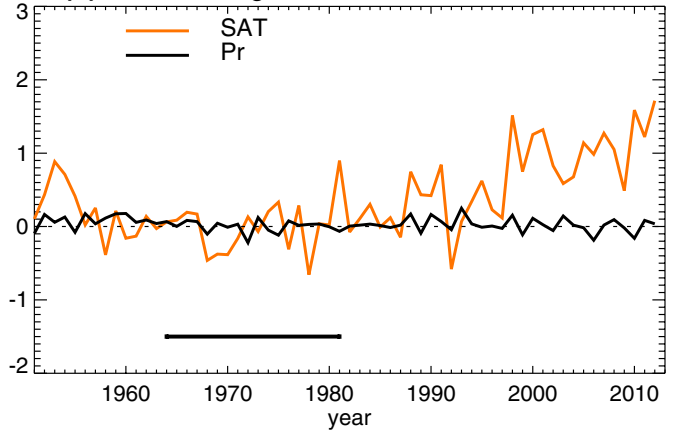

(f) Area averaged indices over South Europe in JJA

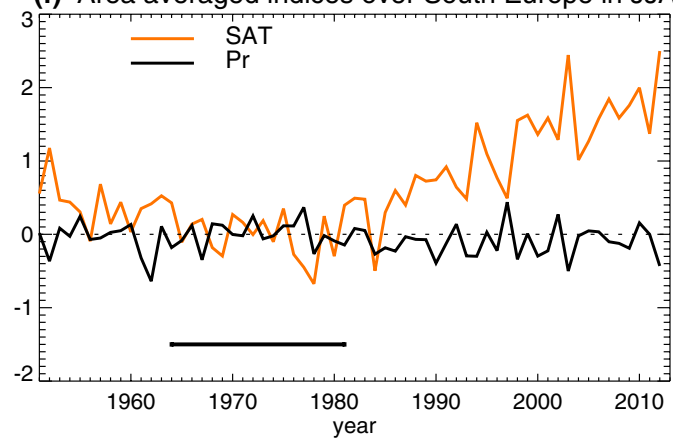

(h) Area averaged indices over North Africa in JJA

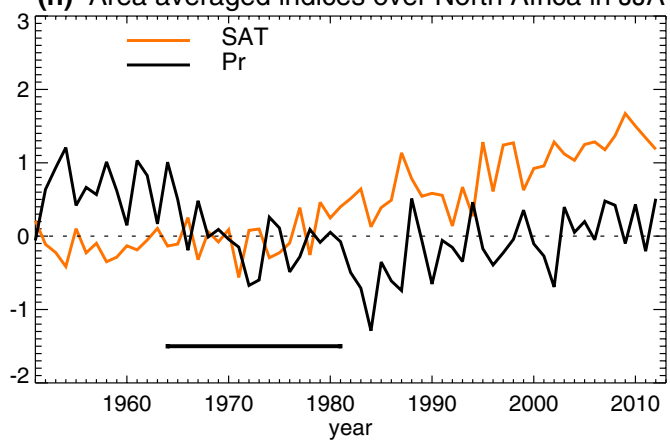

Europe $\left(10^{\circ} \mathrm{W}-40^{\circ} \mathrm{E}, 50^{\circ}-70^{\circ} \mathrm{N}\right)$, f southern Europe $\left(10^{\circ} \mathrm{W}-40^{\circ} \mathrm{E}\right.$, $\left.35^{\circ}-50^{\circ} \mathrm{N}\right)$, g North America $\left(120^{\circ} \mathrm{W}-60^{\circ} \mathrm{W}, 30^{\circ}-60^{\circ} \mathrm{N}\right)$, and $\mathbf{h}$ North Africa $\left(20^{\circ} \mathrm{W}-35\right.$ E, $\left.15^{\circ}-30 \mathrm{~N}\right)$ in JJA. For $\mathbf{h}$, precipitation is averaged over the Sahel $\left(20^{\circ} \mathrm{W}-35^{\circ} \mathrm{E}, 10^{\circ}-20^{\circ} \mathrm{N}\right.$ : black box in Fig. 3d) 
averaged SAT and precipitation anomalies indicate that 2012 was the warmest JFM winter over North America (Fig. 4a). The JFM SAT anomaly in 2012 was $3.9^{\circ} \mathrm{C}$ above the baseline climatology, which is 3.7 standard deviation of the corresponding interannual variability. In addition, JFM 2012 was the second driest year over the Iberian Peninsula since 1951 (Fig. 4b).

In boreal summer (JJA), there is a large-scale warm anomaly with substantial warming maxima over North America, southern Europe, central and eastern Europe, and the Amazon (Fig. 3b), which is accompanied by reduced precipitation over these regions (Fig. 3d) (e.g., Blunden and Arndt 2013; Rupp et al. 2017). Previous studies have suggested land surface feedbacks may play a role in amplifying these local warm anomalies (Dong et al. 2009; Boe and Terray 2014; Dong et al. 2017a). Precipitation anomalies also show a dipole pattern over Europe with an enhancement over North and reduction over South (e.g., Dong et al. 2013; Wilcox et al. 2018), increases over the Sahel (e.g., Parker et al. 2017) and Northeast China (Zhou et al. 2013). The dipole pattern of precipitation anomalies over Europe is associated with negative SLP anomalies over the North Atlantic (Fig. 3e), showing a similar structure to a negative Summer North Atlantic Oscillation (SNAO) (e.g., Folland et al. 2009; Dong et al. 2013).

Time series of area-averaged Northern Hemisphere (NH) SAT anomalies relative to the baseline period (Fig. 4c) indicate that summer 2012 was the second warmest summer since 1951 , with a NH mean SAT anomaly of $1.2^{\circ} \mathrm{C}$ above the baseline climatology of 1964-1981, which is 6.5 times larger than the corresponding standard deviation of interannual variability. There were record regional area-averaged SAT in observations over Eurasia, southern Europe, and North America in 2012 with SAT anomalies of $1.7{ }^{\circ} \mathrm{C}$, $2.5^{\circ} \mathrm{C}, 1.7^{\circ} \mathrm{C}$ above the baseline climatology respectively (Fig. 4d, e, and f). There were also anomalous precipitation deficits over southern Europe and North America of $-0.43 \mathrm{~mm} \mathrm{day}^{-1}$ and $-0.24 \mathrm{~mm} \mathrm{day}^{-1}$ respectively (corresponding to 2.5 and 2.4 interannual standard deviations below the baseline period climatology). The area-averaged precipitation over northern South America shows a deficit of $-0.87 \mathrm{~mm} \mathrm{day}^{-1}$ relative to the baseline period climatology (2.2 interannual standard deviations) while the Sahel experienced increased precipitation of $0.51 \mathrm{~mm} \mathrm{day}^{-1}$ above the baseline climatology (1.2 standard deviations) (Fig. 4h, i).

In contrast to the large positive anomalies in SAT seen over most land regions in JJA, the enhanced precipitation over northern Europe in 2012 is accompanied by a weak negative SAT anomaly (Fig. 4e). In fact, in both northern and southern Europe the interannual variations of SAT and precipitation are negatively correlated in summer, which indicates an influence of land surface feedbacks on SAT variations (Boe and Terray 2014; Dong et al. 2017a).
The spatial patterns of changes in SAT and precipitation for boreal winter and summer, and time series averaged for various regions have also been analyzed based on the University of Delaware (UD) air temperature and precipitation data set (UDel_AirT_Precip) version 4.01 (Willmott and Matsuura 2001), Global Historical Climatology Network (GHCN) gridded V3 SAT data set (Jones and Moberg, 2003) and Global Precipitation Climatology Centre (GPCC) V7 precipitation data set (Schneider et al. 2014). Results indicate that the main features of changes in SAT and precipitation from these different data sets are very similar to those discussed above based on the CRU TS3.21 data set (not shown). This indicates that the anomalous characteristics highlighted above for 2012 are robust and not sensitive to a particular data set.

What factors have played a role in driving the anomalous climate conditions in 2012 in observations? We will investigate physical drivers of the 2012 seasonal mean anomalies, and assess whether the attribution statements for these climate anomalies are sensitive to air-sea coupling using the two sets of numerical experiments introduced in Sect. 2.3.

\section{Global responses in coupled and uncoupled model simulations}

\subsection{Spatial patterns of responses in sea surface temperature (SST)}

The spatial patterns of SST anomalies in boreal winter (JFM) and summer (JJA) of 2012 relative to the baseline period climatology of 1964-1981 in observations and MetUMGOML2 simulations are illustrated in Fig. 5. Observations (Fig. 5a and b) show warm anomalies of $0.4-1.2{ }^{\circ} \mathrm{C}$ over the Indian Ocean, western tropical Pacific, eastern tropical Pacific, North Pacific, and over the North Atlantic and cold anomalies over the central tropical Pacific and south Atlantic in JFM. The large scale pattern of SST anomalies in JJA is similar to that in JFM. The most distinct features in JJA compared to JFM are strong warm anomalies of more than $2.0^{\circ} \mathrm{C}$ over the North Atlantic subpolar gyre and a warming of $0.4-0.8{ }^{\circ} \mathrm{C}$ over the subtropical North Atlantic.

The simulated SST responses to 2012 anthropogenic forcing relative to the simulation for the baseline period of 1964-1981 are shown in Fig. 5c and d. These simulated SST anomalies suggest some contribution of changes in anthropogenic forcing to the seasonal SST anomalies in observations. Half of the magnitude of observed SST anomalies in the Southern Ocean, tropical Indian Ocean, western tropical Pacific, subtropical North Atlantic in JJA and North Atlantic in JFM can be attributed to changes in anthropogenic forcing. However, other SST features, especially the cold anomalies in observations in some regions in both seasons 
(a) JFM Obs. SST change 2012-(1964to1981)

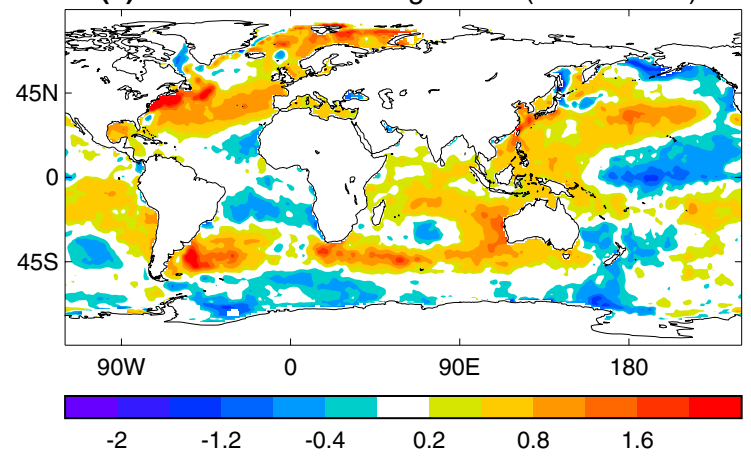

(c) JFM Simulated SST change (Coupled)

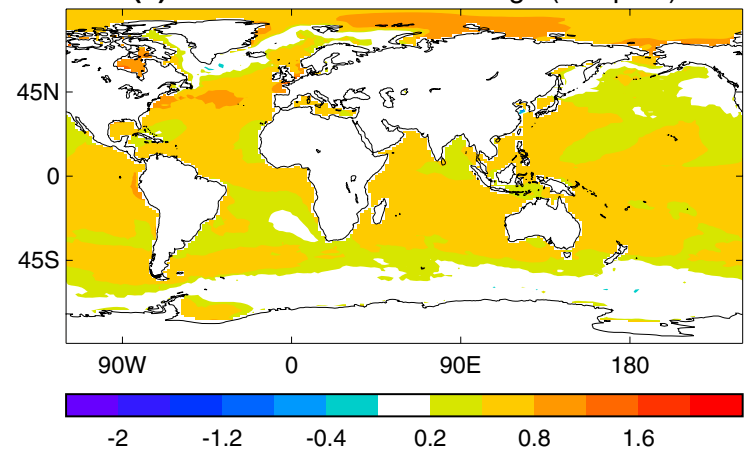

(b) JJA Obs. SST change 2012-(1964to1981)

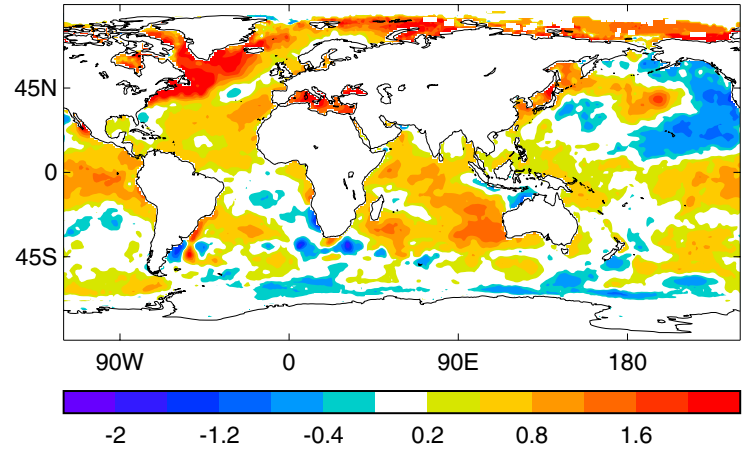

(d) JJA Simulated SST change (Coupled)

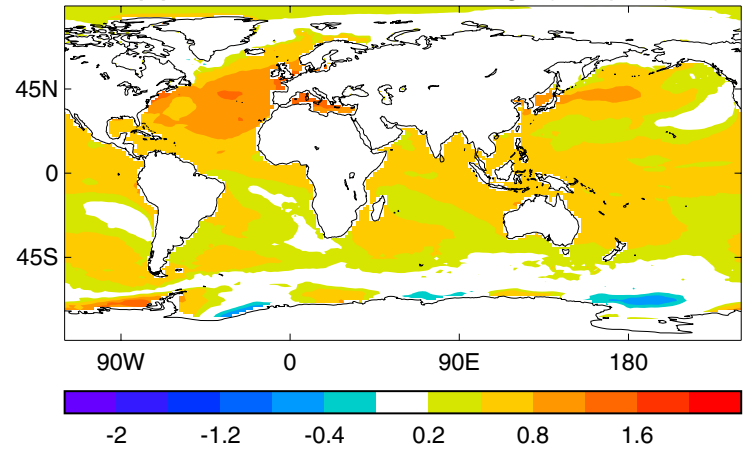

Fig. 5 Sea surface temperature $\left({ }^{\circ} \mathrm{C}\right.$ ) differences between 2012 and the reference period (1964-1981, clim) for JFM (left panel) and JJA (right panel). $\mathbf{a}$ and $\mathbf{b}$ Are based on HadISST. $\mathbf{c}$ and $\mathbf{d}$ are MetUM-GOML2 model simulations (C2012-Cclim)

are not simulated and the model underestimates large observed warming over the North Atlantic subpolar gyre in JJA, implying a role of internal variability for these observed anomalies or model deficiency in response to changes in forcing.

\subsection{Spatial patterns of responses in SAT}

In boreal winter, both the coupled and uncoupled model responses to 2012 anthropogenic forcing relative to the simulation for the baseline period of 1964-1981 show large scale SAT warming over land in JFM, including North and South America, Africa, Australia, and large area of Asian continent (Fig. 6a and c). These features are similar in the coupled and uncoupled model experiments, indicating an insensitivity of SAT responses over these regions to air-sea coupling. However, the SAT responses over mid-latitudes over the Northern Hemisphere show some differences. In particular, the SAT response over the eastern North America, Western Europe, and central and eastern Asia in the uncoupled experiments shows a warming that is weaker by about $0.25-0.5{ }^{\circ} \mathrm{C}$ (significant at the $10 \%$ level) relative to the coupled response (Fig. 6e), implying a role for air-sea coupling in SAT responses in these NH mid-latitude regions.
In boreal summer, both the coupled and uncoupled experiments give some similar SAT changes in spatial pattern in response to changes in anthropogenic forcing (Fig. 6b and d). However, quantitatively, responses in the uncoupled model simulations show relatively weaker warming over the eastern North America, central Europe, and Northeastern Asia (Fig. 6f), again over the NH mid-latitude regions, suggesting a role for air-sea coupling in these regional SAT responses.

\subsection{Spatial patterns of responses in circulation and precipitation}

The anomalies in SLP for JFM and JJA in response to changes in anthropogenic forcing in 2012 in the coupled and uncoupled experiments are illustrated in Fig. 7 and those in precipitation over land are shown in Fig. 8. Over the Northern Hemisphere in boreal winter (JFM), the coupled model responses show anomalous high pressure over the mid-latitude in North Atlantic and anomalous low pressure to the north, extending south-eastward across the Eurasian continent (Fig. 7a). This anomalous circulation pattern has similar characteristics to a positive NAO with anomalous westerlies across the U.K. and into central Europe. In contrast, the responses in uncoupled simulations show a band of low 
(a) JFM Simulated SAT change (Coupled)

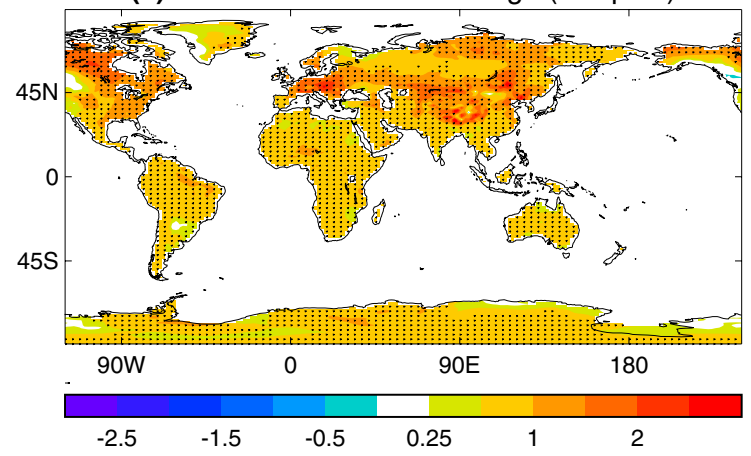

(c) JFM Simulated SAT change (Uncoupled)

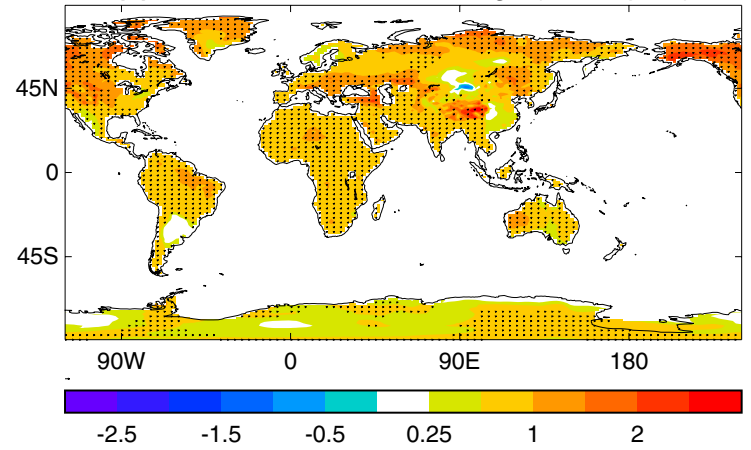

(e) JFM Simulated SAT change (difference)

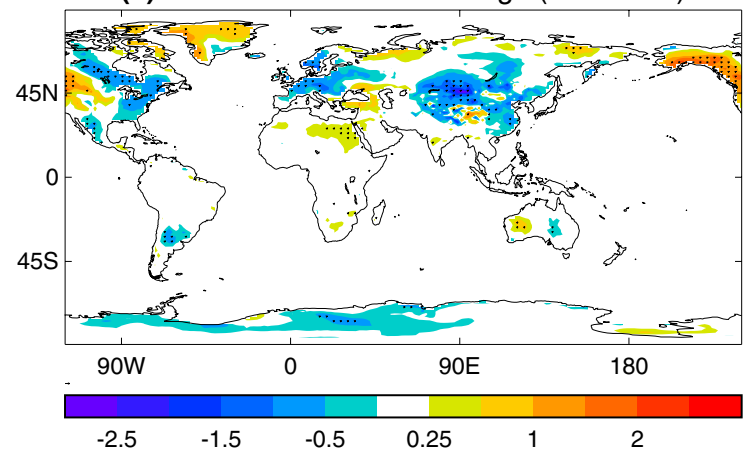

Fig. 6 Surface air temperature $\left({ }^{\circ} \mathrm{C}\right)$ changes for JFM (left panel) and JJA (right panel) in MetUM-GOML2 model simulations. a and b are for coupled simulations (C2012-Cclim). $\mathbf{c}$ and $\mathbf{d}$ are for uncoupled simulations (A2012-Aclim). e and $\mathbf{f}$ are differences between the

pressure anomalies, extending from North America, across the mid-latitude of North Atlantic and into southern Europe (Fig. 7c) with anomalous northeasterlies along the coast of Western Europe. These differences result in a dipole pattern of SLP anomalies with significant negative differences and lower tropospheric cyclonic circulation anomalies over the mid-latitudes of the Atlantic sector and significant positive differences to the north between the coupled and uncoupled simulation (Fig. 7e). As a result, SAT warm anomalies in the coupled model response are stronger over Western Europe and central Asia (Fig. 6a, c, e). Also associated with the (b) JJA Simulated SAT change (Coupled)

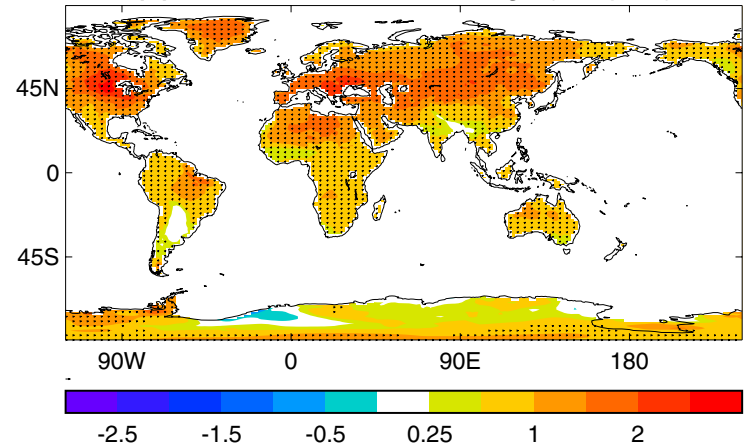

(d) JJA Simulated SAT change (Uncoupled)

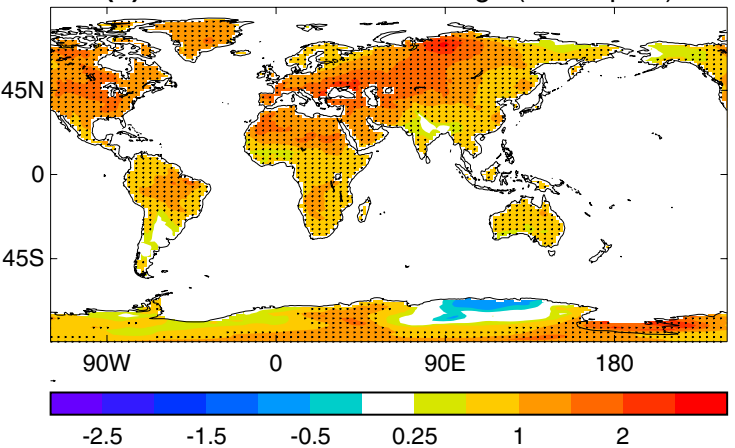

(f) JJA Simulated SAT change (difference)

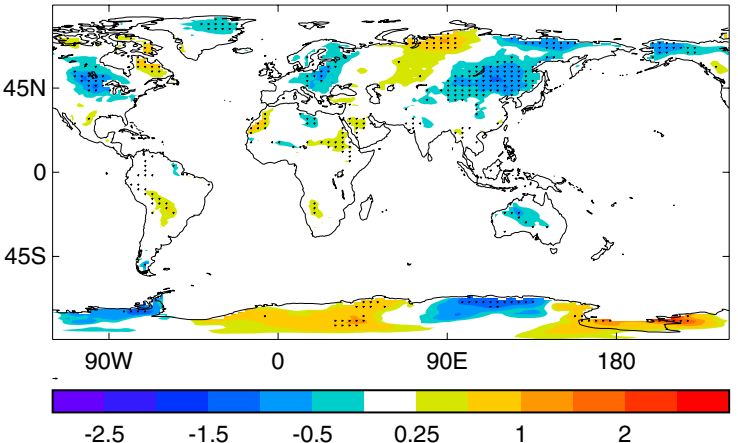

uncoupled and coupled changes. Dots highlight regions where the changes are statistically significant at the $10 \%$ level based on a twotailed Student's t test

positive NAO-like circulation anomalies in JFM in the coupled model simulations (Fig. 7a), the precipitation response has wet anomalies over the UK and Western Europe and dry anomalies over the Iberian Peninsula (Fig. 8a). However, the uncoupled experiments show wet anomalies over both Western Europe and the Iberian Peninsula (Fig. 8c), which are associated with local low pressure anomalies (Fig. 7c). These results indicate a sensitivity of circulation and precipitation responses over the North Atlantic and Western Europe to air-sea interaction in boreal winter. 

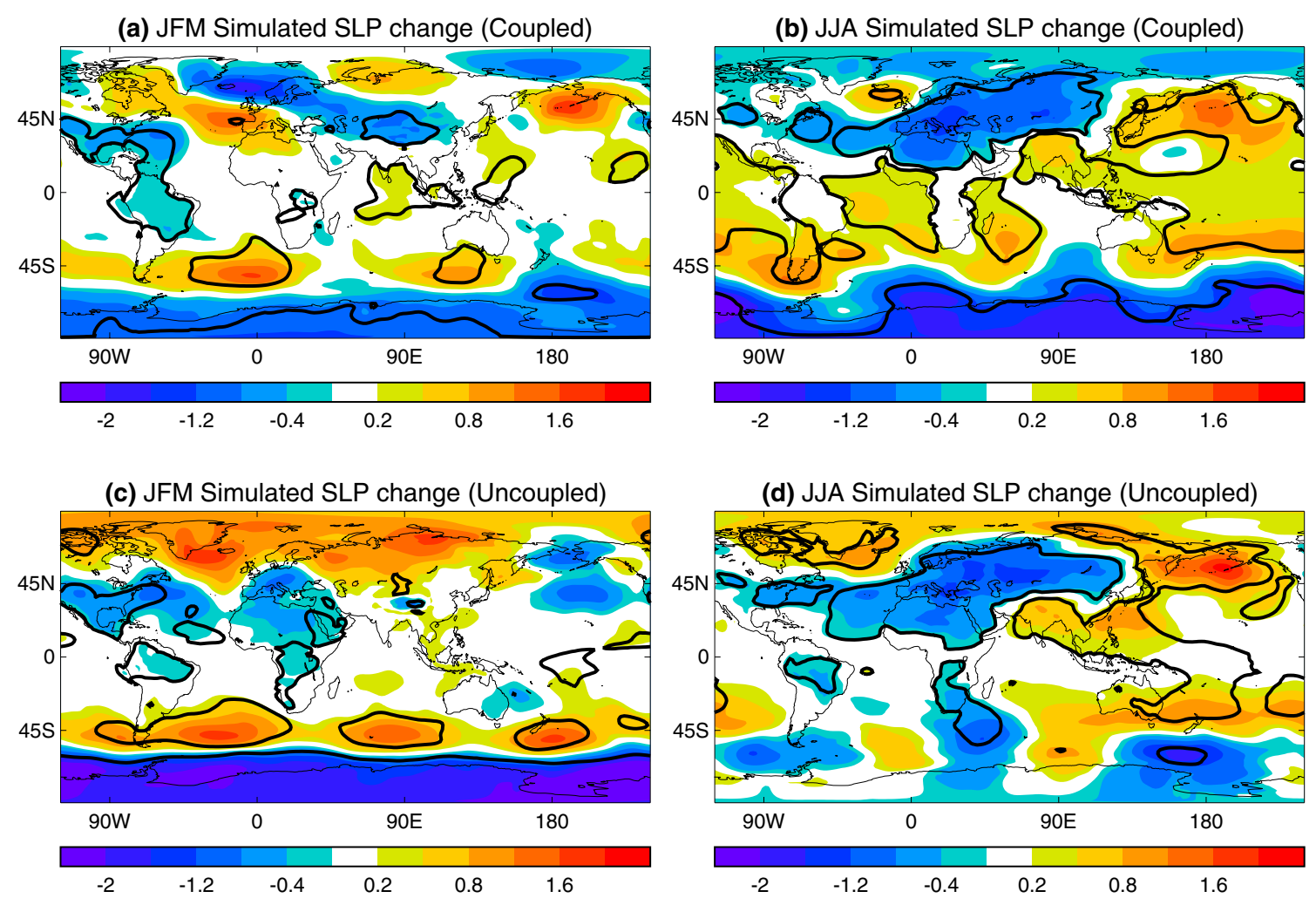

(e) JFM Simulated SLP change (difference)

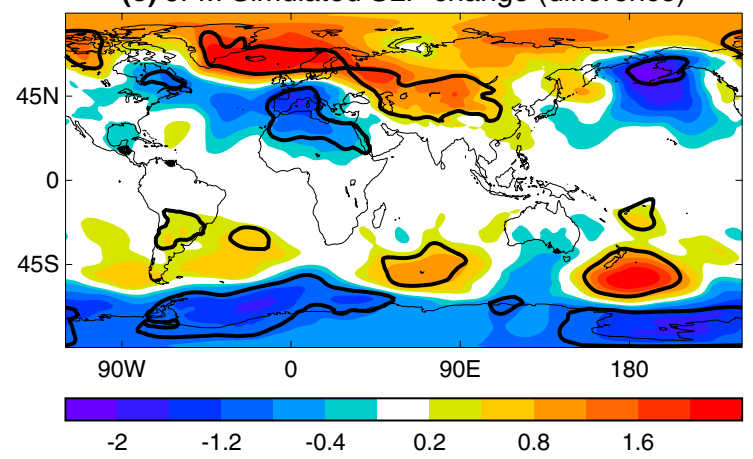

Fig. 7 Sea level pressure (SLP) (hPa) changes for JFM (left panel) and JJA (right panel) in MetUM-GOML2 model simulations. a and $\mathbf{b}$ are for coupled simulations (C2012-Cclim). c and $\mathbf{d}$ are uncoupled simulations (A2012-Aclim). e and $\mathbf{f}$ show differences between the

Changes in SLP in the Southern Hemisphere in JFM show a dipole pattern with low anomalies over the Antarctic and high anomalies around $45^{\circ} \mathrm{S}$, projecting onto the positive phase of the southern annular mode (SAM) (e.g., Fyfe et al. 1999) with anomalous westerlies around the Ataractic. Both the coupled and uncoupled model simulations give similar changes, but the magnitude is stronger in the uncoupled simulations (Fig. 7a, c, and e) although the resultant SAT and precipitation differences are weak over the Antarctic (Figs. 6 and 8).

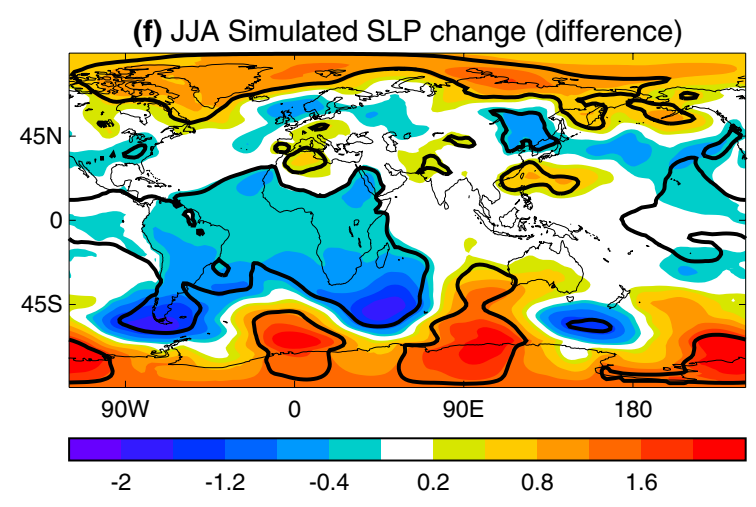

uncoupled and coupled changes. Thick black lines highlight regions where the changes are statistically significant at the $10 \%$ level based on a two-tailed Student's t test

In boreal summer, the SLP anomalies are much more consistent between the coupled and uncoupled simulations in the Northern Hemisphere (Fig. 7b and d). The pattern over the North Atlantic is characteristic of the negative phase of the summer North Atlantic Oscillation (SNAO; Folland et al. 2009; Dong et al. 2013). Associated with the negative SNAO-like circulation pattern, both the coupled and uncoupled simulations indicate increased precipitation over northern Europe (Fig. 8b, and d). In addition, both simulations indicate enhanced precipitation over the Sahel, and 
(a) JFM Simulated Pr change (Coupled)

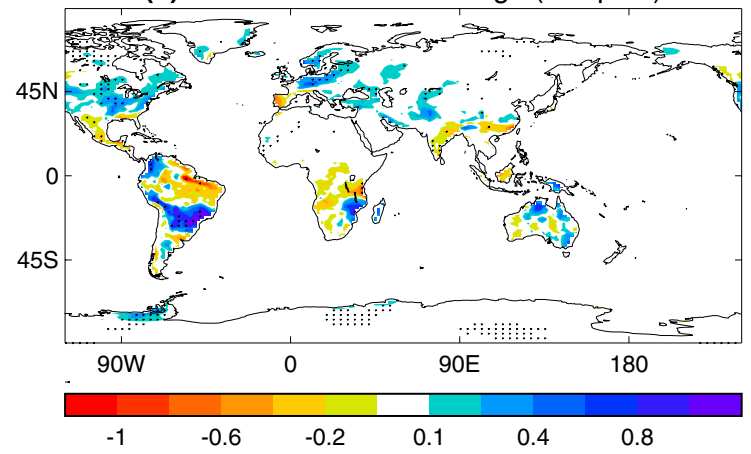

(c) JFM Simulated Pr change (Uncoupled)

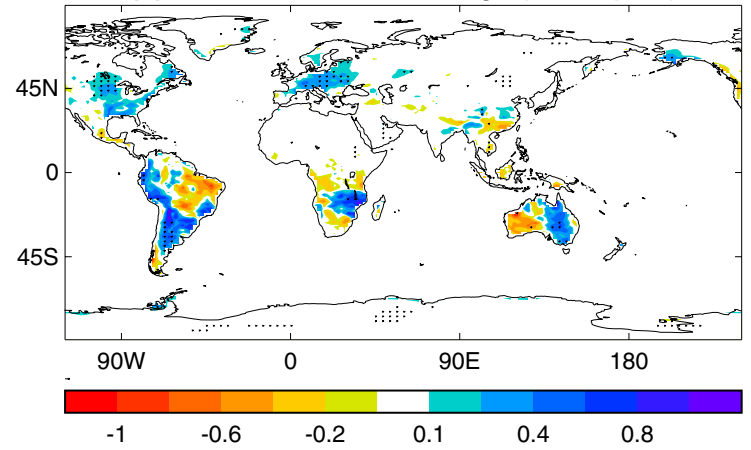

(e) JFM Simulated Pr change (difference)

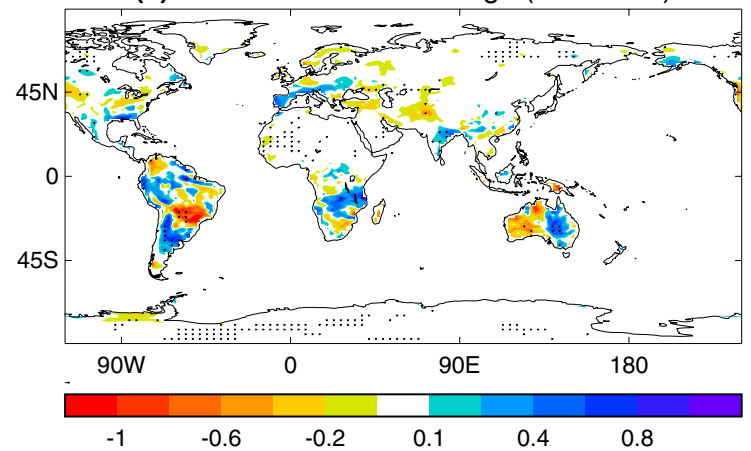

Fig. 8 Precipitation (mm day ${ }^{-1}$ ) changes for JFM (left panel) and JJA (right panel) in MetUM-GOML2 model simulations. a and $\mathbf{b}$ are for coupled simulations (C2012-Cclim). $\mathbf{c}$ and $\mathbf{d}$ are for the uncoupled simulations (A2012-Aclim). e and $\mathbf{f}$ show differences between the

reduced precipitation over North and South America. As for SLP, all these features appear to be insensitive to the inclusion of air-sea interactions (Fig. 8b, d, and f).

SLP and lower tropospheric circulation anomalies over East Asia, the western tropical Pacific, and over the Southern Hemisphere in boreal summer show some differences between the coupled and uncoupled simulations (Fig. 7b, $\mathrm{d}$ and $\mathrm{f}$ ). The coupled model simulations show weaker SLP changes over the western tropical Pacific while the uncoupled simulations show significant increases. In the coupled model simulation, these changes in SLP are associated with (b) JJA Simulated Pr change (Coupled)

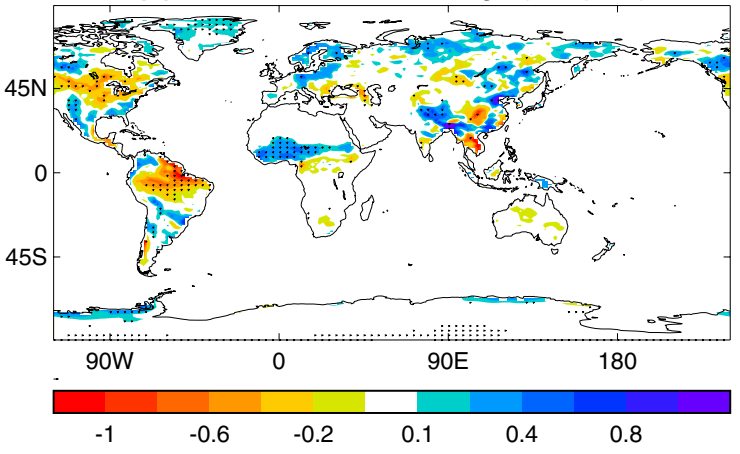

(d) JJA Simulated Pr change (Uncoupled)

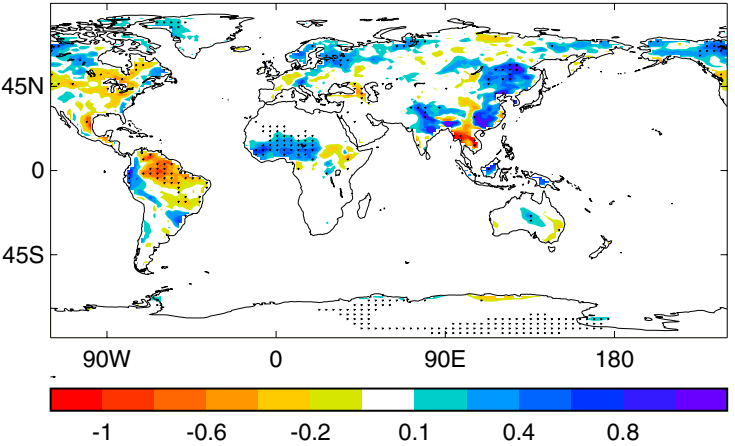

(f) JJA Simulated Pr change (difference)

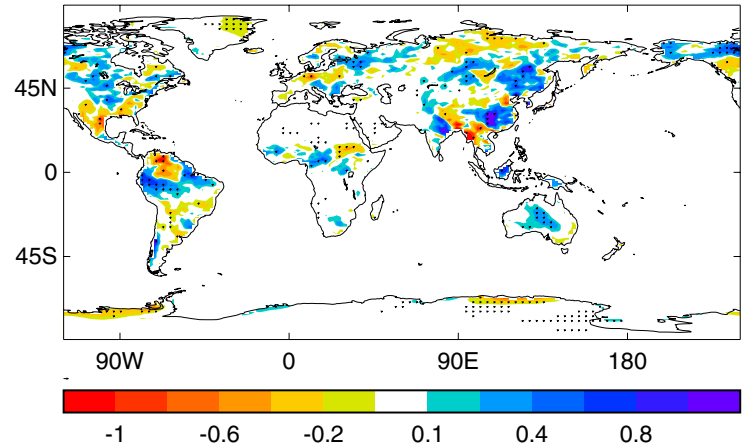

uncoupled and coupled changes. Dots highlight regions where the changes are statistically significant at the $10 \%$ level based on a twotailed Student's t test

weak changes in low tropospheric circulation. However, in the uncoupled simulation positive SLP anomalies over the western tropical Pacific are associated with anomalous southwesterlies along the coast of East Asia (this will be discussed in detail in Sect. 4.5). This gives rise to weak precipitation changes over East Asia in the coupled simulation, but strong precipitation increases in the uncoupled simulation (Fig. 8b, d and f). These results indicate that responses in both circulation and precipitation over East Asia and the adjacent oceans in boreal summer are sensitive to air-sea interaction. 
In summary, large scale patterns of SAT response to 2012 anthropogenic forcing relative to the simulation for the baseline period of 1964-1981 appear to be largely insensitive to the representation of air-sea interactions, especially over the tropics and Southern Hemisphere in both boreal winter and summer. However, the response in large-scale circulation over the Atlantic sector in boreal winter is sensitive to air-sea interaction. This leads to some differences in the SAT and precipitation response over North America and Western Europe between the coupled and uncoupled simulations. In boreal summer, the response of the East Asian summer monsoon circulation, local precipitation, and SAT shows some contrasting features between the coupled and uncoupled simulations, suggesting that air-sea coupling may play a role in shaping the climate response to 2012 forcing over East Asia.

\subsection{Interpreting different responses over the Atlantic sector in boreal winter}

In Sect. 4.3, it was shown that boreal winter circulation and precipitation responses to anthropogenic forcing in 2012 over the North Atlantic sector and Western Europe were significantly different in the coupled and uncoupled simulations. This indicates that air-sea interaction may be important for these regional responses. Section 4.4 addresses the question, which processes are responsible for these differences?

Shown in Fig. 9 are responses of precipitation and circulation over the Atlantic sector in JFM. There are some contrasting features of precipitation responses in the coupled and uncoupled simulations. The coupled response shows a significant decrease over the Gulf of Mexico and a significant increase to the east (Fig. 9a). In contrast, the response
Fig. 9 Changes in $\mathbf{a}, \mathbf{b}$ precipitation $\left(\mathrm{mm} \mathrm{day}^{-1}\right)$, $\mathbf{c}$ and $\mathbf{d}$ $\mathrm{SLP}(\mathrm{hPa})$ and $850 \mathrm{hPa}$ wind $\left(\mathrm{m} \mathrm{s}^{-1}\right)$ and $\mathbf{e}$ and $\mathbf{f}$ streamfunction $\left(10^{6}\right)$ at $200 \mathrm{hPa}$ over the North Atlantic sector for JFM in MetUM-GOML2 model simulations. $\mathbf{a}, \mathbf{c}$, and $\mathbf{e}$ are for coupled simulations (C2012-Cclim). b, $\mathbf{d}$, and $\mathbf{f}$ are for uncoupled simulations (A2012-Aclim). Dots (a, b) and thick lines (c-f) highlight regions where the changes are statistically significant at the $10 \%$ level based on a two-tailed Student's t test (a) precipitation (Coupled) in JFM

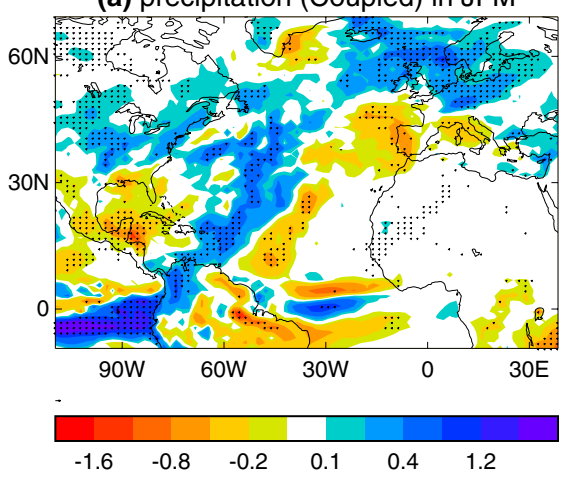

(c) SLP and $850 \mathrm{hPa}$ wind (Coupled) in JFM

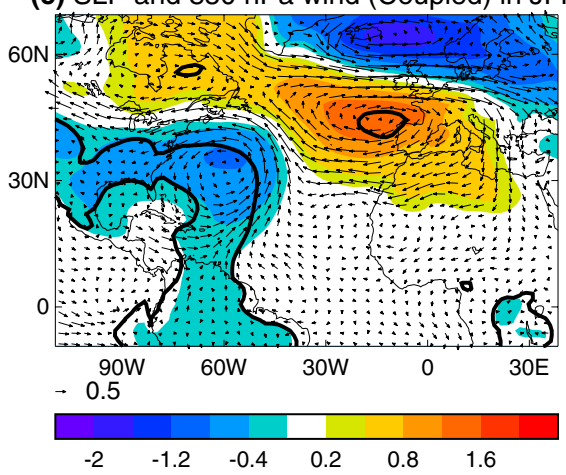

(e) $200 \mathrm{hPa}$ streamfuction (Coupled) in JFM

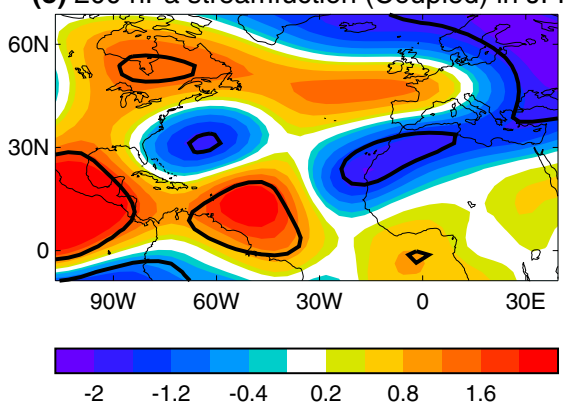

(b) precipitation (Uncoupled) in JFM

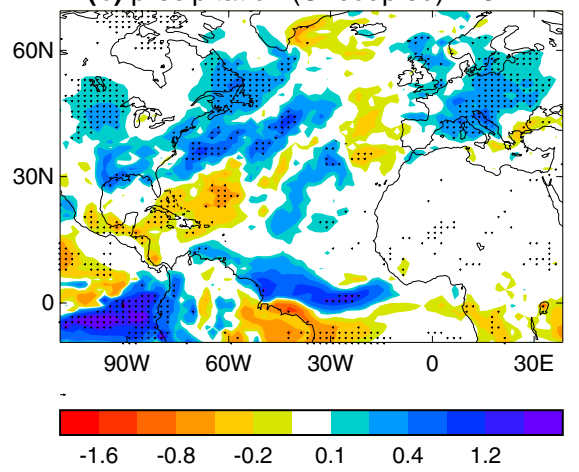

(d) SLP and $850 \mathrm{hPa}$ wind (Uncoupled) in JFM

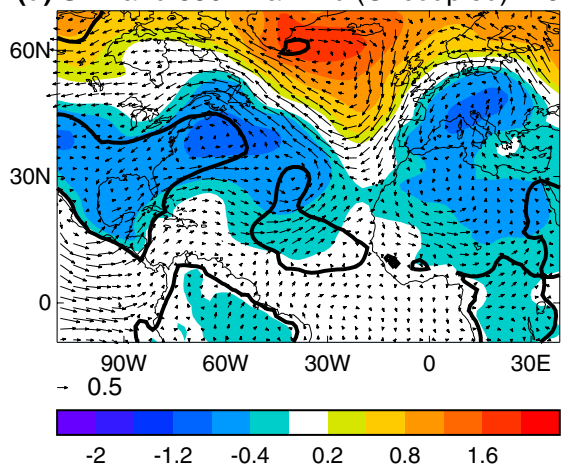

(f) $200 \mathrm{hPa}$ streamfuction (Uncoupled) in JFM

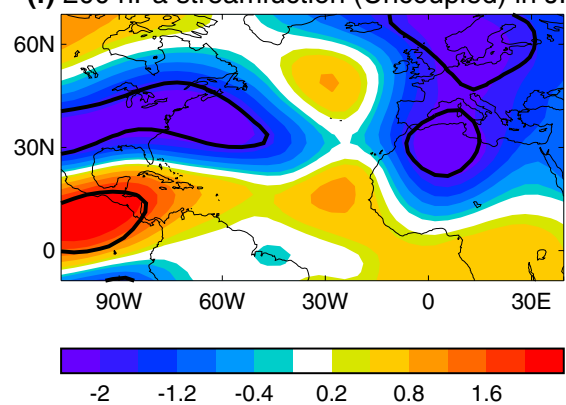


in the uncoupled simulations shows increased precipitation in the northern subtropics and decreased precipitation over and to the east of the Caribbean (Fig. 9b). Some of those differences in the North Atlantic circulation and precipitation responses might be related to differences of precipitation and diabatic heating anomalies in the tropical Pacific and tropical Atlantic where Rossby waves generated can affect the North Atlantic (Yu and Lin 2016; Watson et al. 2016; Scaife et al. 2017).

Following Sardeshmukh and Hoskins (1988), Shimizu and Cavalcanti (2011), the Rossby wave source is calculated as $-\nabla \cdot \mathbf{v}_{\chi}(\zeta+\mathrm{f})=-(\zeta+\mathrm{f}) \nabla \cdot \mathbf{v}_{\chi}-\mathbf{v}_{\chi} \cdot \nabla(\zeta+\mathrm{f})$. Here $\mathbf{v}_{\chi}$ is the divergent part of the horizontal wind, $\zeta$ is the relative vorticity, and $f$ is the planetary vorticity with the first term on the right representing vorticity generation associated with horizontal divergence and the second term representing vorticity advection by the divergent wind.

As shown in Fig. 10, there are some contrasting precipitation changes in the tropical oceanic regions between the coupled and uncoupled model simulations in JFM (Fig. 10a and b). The changes in precipitation are weak over the tropical Atlantic in the coupled model. This is in contrast with the uncoupled simulation where there are significant increases in precipitation in the northern tropical Atlantic. Another region where there are significant contrasts in precipitation changes are over the tropical Western Pacific where coupled model gives weak changes while uncoupled model shows significantly enhanced precipitation. In addition, precipitation changes over the tropical Indian Ocean are also showing some differences. The contrasting precipitation anomalies (Fig. 10a and b) between the coupled simulations and uncoupled simulations result in different Rossby wave source anomalies in the upper troposphere (Fig. 10c and d). These results are consistent with recent studies (Yu and Lin 2016; Watson et al. 2016; Scaife et al. 2017) that suggested the precipitation and diabatic heating anomalies over tropical regions may play an important role in winter interannual variability and predictability of the North Atlantic atmospheric circulation. Therefore, diabatic heating contrasts associated with different precipitation changes over the tropical Pacific and tropical Atlantic in the coupled and uncoupled model simulations might contribute to the different circulation responses over the North Atlantic. The result is that positive NAO-like circulation anomalies over the North Atlantic sector lead to a dipole pattern of precipitation anomalies over Western Europe. This dipole pattern has increased precipitation over northern Europe and decreased precipitation over southern Europe in the coupled model simulations. While in the uncoupled model simulations, the anomalous cyclonic circulation over Western Europe is associated with increase in precipitation over a larger domain, leading to less warming in the uncoupled model simulation in comparison with the coupled model simulation (Fig. 6e). (a) JFM Simulated Pr change (Coupled)
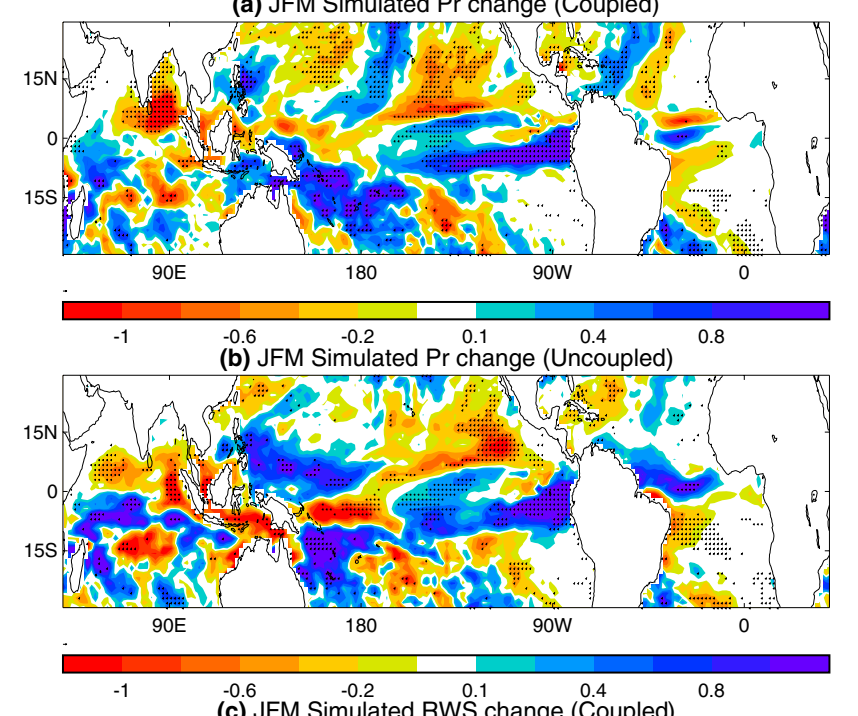

(c) JFM Simulated RWS change (Coupled)

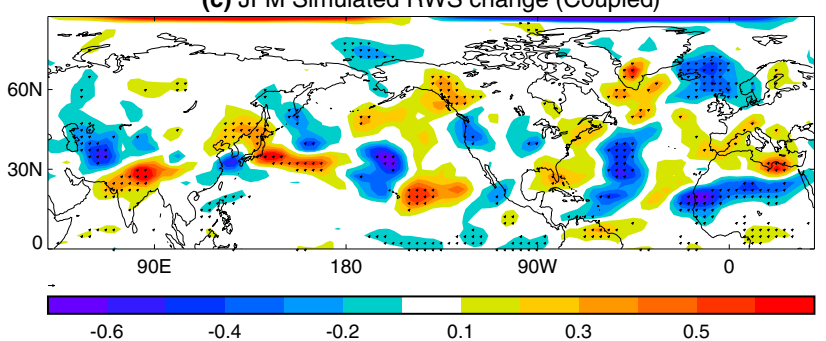

(d) JFM Simulated RWS change (Uncoupled)

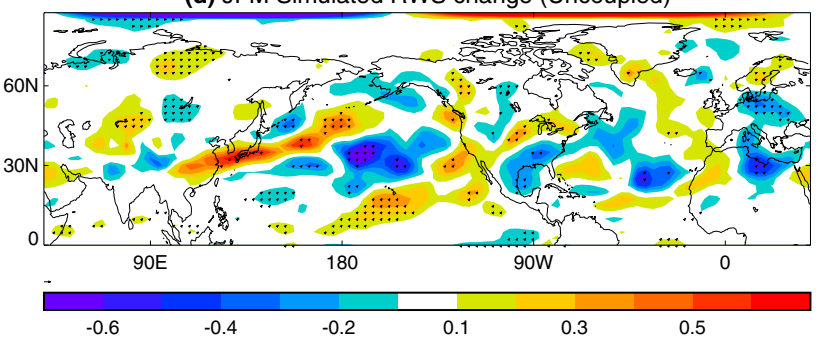

Fig. 10 Changes in $\mathbf{a}, \mathbf{b}$ precipitation $\left(\mathrm{mm} \mathrm{day}^{-1}\right), \mathbf{c}$ and $\mathbf{d}$ Rossby wave source $\left(10^{-10} \mathrm{~s}^{-2}\right)$ at $200 \mathrm{hPa}$ for JFM in MetUM-GOML2 model simulations. a, c Are for coupled simulations (C2012-Cclim). b, e Are for uncoupled simulations (A2012-Aclim). Dots highlight regions where the changes are statistically significant at the $10 \%$ level based on a two-tailed Student's t test

\subsection{Interpreting different responses over East Asia and adjacent oceans in boreal summer}

In Sect. 4.3, it was shown that circulation and precipitation responses to anthropogenic forcing in 2012 over East Asia and adjacent oceans are sensitive to air-sea interaction. Some differences of spatial patterns in the responses between the coupled and uncoupled model simulations are further illustrated in Fig. 11. The responses in surface energy budget components and vertical velocity are shown in Fig. 12. One of the most strongly contrasting features is over the Maritime Continent (MC) where coupled simulations show weak 
(a) precipitation (Coupled) in JJA
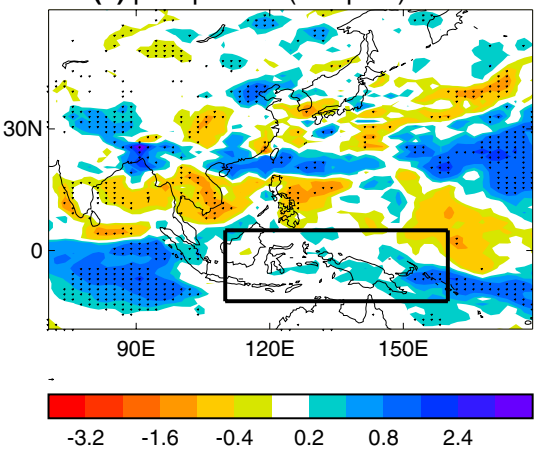

(d) SLP and $850 \mathrm{hPa}$ wind (Coupled) in JJA

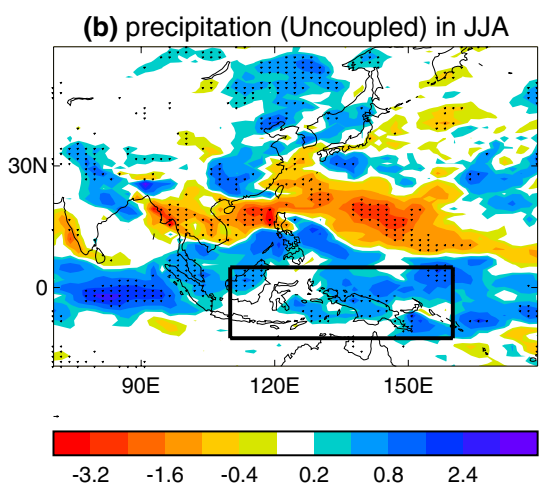

(e) SLP and $850 \mathrm{hPa}$ wind (Uncoupled) in JJA (c) JJA Obs. Pr. change 2012-(1964to1981)
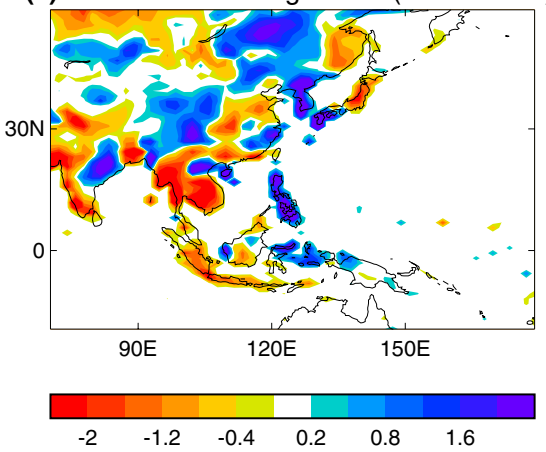

(f) JJA Obs. SLP and $850 \mathrm{hPa}$ wind change
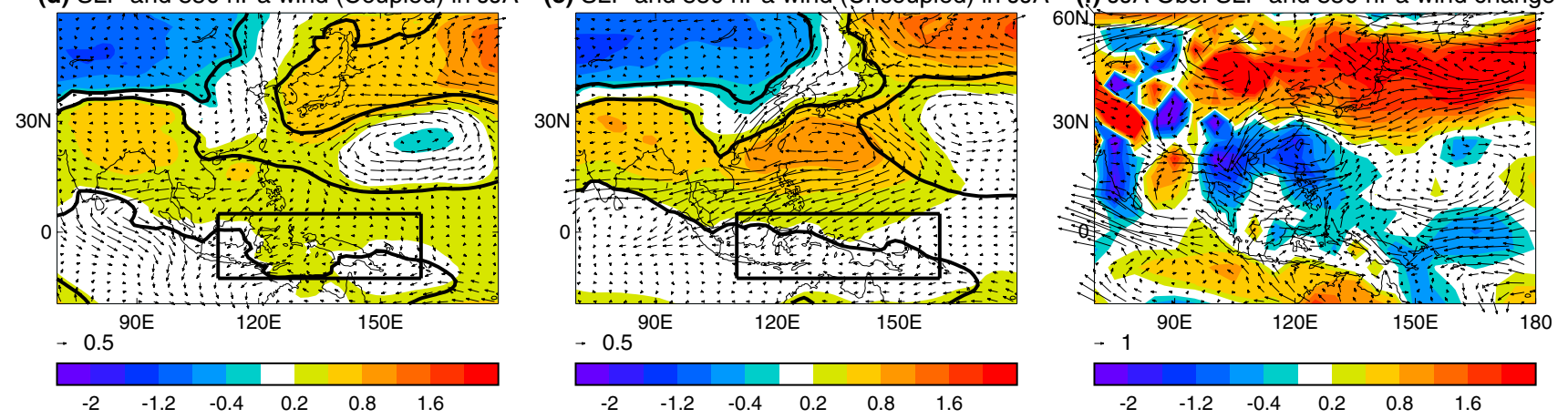

Fig. 11 Simulated and observed changes in a-c precipitation ( $\mathrm{mm}$ day $\left.^{-1}\right)$, d-f SLP (hPa) and $850 \mathrm{hPa}$ wind $\left(\mathrm{m} \mathrm{s}^{-1}\right)$ for JJA. a and d are for coupled simulations (C2012-Cclim). $\mathbf{b}$ and $\mathbf{e}$ are for uncoupled simulations (A2012-Aclim). c Precipitation difference between 2012 and climatological period (1964-1981) in JJA based on CRUTS3.21

and f SLP difference based on HadSLP2r and $850 \mathrm{hPa}$ wind difference based on NCEP-reanalysis. Dots $(\mathbf{a}, \mathbf{b})$ and thick lines $(\mathbf{d}, \mathbf{e})$ highlight regions where the changes are statistically significant at the $10 \%$ level based on a two-tailed Student's t test

changes in precipitation while uncoupled simulations indicate significantly enhanced precipitation (Fig. 11a, b). The weak precipitation changes in the coupled model simulations are associated with weak changes in lower tropospheric convergence and vertical velocity over both the MC and the tropical western Pacific (Figs. 11d, 12c). As a result, circulation anomalies over the tropical western Pacific are also weak, leading to weak changes in precipitation over large land area over East Asia. The strong increases in precipitation over the MC in the uncoupled simulations result from anomalous convergence in the lower troposphere (Fig. 11b, e). This is associated with anomalous ascent over the MC and anomalous descent around $20^{\circ}-25^{\circ} \mathrm{N}$ (Figs. 11e, 12d), indicating a change in the local Hadley circulation. This anomalous descent is associated with an anomalous anticyclonic circulation over the tropical western Pacific in the uncoupled model simulation (Fig. 11e), resulting in less precipitation there, more moisture transport at the western ridge of the anomalous anticyclonic circulation along the coast of East Asia, and more precipitation over large areas of East Asia (Fig. 11b).

The surface energy budget components in the coupled and uncoupled model simulations also show some differences (Fig. 12). The contrasts are mainly reflected in surface shortwave (SW) cloud radiative effect (CRE), and therefore SW changes (Fig. 12e). In both the coupled and uncoupled model simulations, increased GHGs and surface warming leads to increased water vapor in the atmosphere and increased surface longwave (LW) radiation. However, in the coupled model simulations the response shows positive anomalies in SW CRE, related to a decrease in cloud cover (not shown), and reduction of upward turbulent heat fluxes. Overall, this results in net positive changes in total surface heat flux (Fig. 12a), leading to the surface warming over the MC seen in Fig. 5d. When this warming is prescribed in the uncoupled model simulations it leads to enhanced convection and therefore increased precipitation over the MC, leading to negative anomalies in SW CRE associated with the increase in cloud cover (Fig. 12e).

These results suggest that air-sea interaction over the $\mathrm{MC}$ is fundamental for the attribution of East Asian circulation and precipitation responses due to anthropogenic forcing changes seen in 2012 relative the baseline period of 1964-1981. This is consistent with earlier studies that have demonstrated the key role of air-sea interaction for simulating the climate of East Asia (Hu et al. 2012; Zhu and Shukla 2013; Lin et al. 2016) and attributing forced decadal climate change over East Asia (Dong et al. 2017b). 
Fig. 12 Simulated changes in $\mathbf{a}, \mathbf{b}$ surface total heat flux $\left(\mathrm{W} \mathrm{m}^{-2}\right)$, $\mathbf{c}$ and $\mathbf{d}$ zonally averaged vertical velocity $\left(10^{-2} \mathrm{~Pa} \mathrm{~s}^{-1}\right)$ over the western Pacific sector $\left(110^{\circ}-160^{\circ} \mathrm{E}\right)$ for JJA. $\mathbf{a}$ and $\mathbf{c}$ are for coupled simulations (C2012-Cclim). b and $\mathbf{d}$ are for uncoupled simulations (A2012-Aclim). Dots (a, b) and thick lines (c, d) highlight regions where the changes are statistically significant at the $10 \%$ level based on a two-tailed Student's t-test. e area averaged variables (SAT for surface air temperature in ${ }^{\circ} \mathrm{C}, \operatorname{Pr}$ for precipitation in $\mathrm{mm} \mathrm{day}^{-1}, \mathrm{WV}$ for vertically integrated water vapor in $\mathrm{kg} \mathrm{m}^{-2}$, AOD for aerosol optical depth) and surface energy components (SW for shortwave, LW for longwave, CSW for clear sky shortwave, CLW for clear sky longwave, CRESW for shortwave cloud radiative effect, CRELW for longwave cloud radiative effect. SH for sensible flux, and LH for latent heat flux) over the Maritime Continent (black box shown in panels $\mathbf{a}$ and $\mathbf{b}$ ). Surface energy components are in $\mathrm{W} \mathrm{m}^{-2}$ with positive values mean downward)

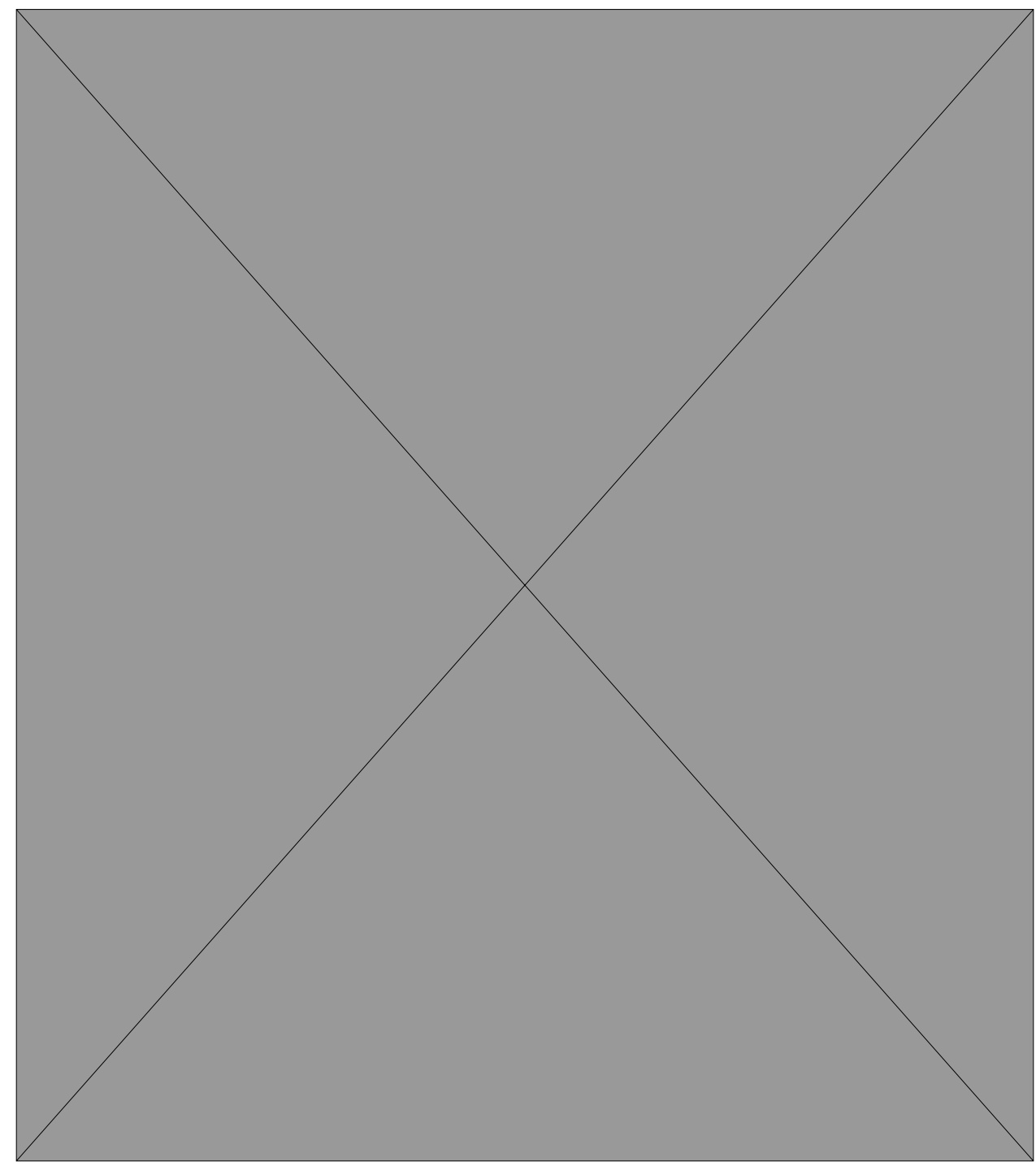

\section{Comparison of model simulated changes with observations}

Neither the coupled nor uncoupled model reproduces the 2012 observed SAT anomalies over Eurasia in JFM (a dipole pattern of warm anomalies in high latitude and cold anomalies in mid-latitude: Figs. 3a, 6a and c). The differences between the model responses and the observed changes might reflect a model deficiency in its response to the 2012 anthropogenic forcing change. On the other hand, they might also reflect missing drivers, such as sea ice extent change, that are not represented in model experiments (e.g., Mori et al. 2014). Alternatively, the differences would also be consistent with the idea that the internal variability played an important role in shaping the 2012 SAT changes over mid-high latitudes in the Northern Hemisphere in boreal winter in observations.
The differing model responses show that JFM circulation and precipitation changes over the North Atlantic sector are sensitive to the representation of air-sea interaction (Figs. 3, 7, and 8). Coupled model responses show positive NAOlike circulation anomalies over the North Atlantic sector (Fig. 7a), with anomalous westerlies across the U.K. and into central Europe. This leads to a dipole pattern of precipitation anomalies over Western Europe with dry anomalies over the Iberian Peninsula (Fig. 8a), although with a weaker than observed magnitude (Fig. $3 \mathrm{c}$ and e). In contrast, the uncoupled experiment does not capture these observed features in circulation and precipitation (Figs. 7c, 8c).

In contrast, large scale patterns of SAT changes in boreal summer in the coupled and uncoupled model experiments show similar features and are also similar to the pattern of observed changes (Figs. 3b, 6b and d). Both coupled and uncoupled model simulations reproduce observed changes qualitatively in various regions where 
observations showed extreme seasonal mean anomalies in 2012 (Fig. 13). The good agreement between the changes in SAT found in models and in observations suggest that SAT changes in 2012 boreal summer are predominantly induced by changes in anthropogenic forcing.
In boreal summer, both the coupled and uncoupled model simulations show a negative SNAO-like circulation anomaly over the North Atlantic sector, with increased precipitation over northern Europe (Figs. $7 b$ and d, $8 b$ and d, 13e and f). Additionally, both simulations indicate enhanced precipitation over the Sahel, and reduced precipitation over North
Fig. 13 Observed and model simulated seasonal mean changes for SAT and precipitation over various regions (land only) outlined in Fig. 3. The unit is in ${ }^{\circ} \mathrm{C}$ for temperature and in $\mathrm{mm} \mathrm{day}^{-1}$ for precipitation $(\mathrm{Pr})$. Observed changes are based on CRUTS3.21. The coloured bars indicate the central estimates and the whiskers show the $90 \%$ confidence intervals. These regions are a North America $\left(120^{\circ}-60^{\circ} \mathrm{W}, 30^{\circ}-60^{\circ} \mathrm{N}\right)$, b Iberian Peninsula $\left(10^{\circ} \mathrm{W}-5^{\circ} \mathrm{E}\right.$, $35^{\circ}-45^{\circ} \mathrm{N}$ ) in JFM, c Northern Hemisphere, $\mathbf{d}$ Eurasia $\left(30^{\circ}-120^{\circ} \mathrm{E}, 40^{\circ}-70^{\circ} \mathrm{N}\right)$, e northern Europe $\left(10^{\circ} \mathrm{W}-40^{\circ} \mathrm{E}\right.$, $\left.50^{\circ}-70^{\circ} \mathrm{N}\right)$, f southern Europe $\left(10^{\circ} \mathrm{W}-40^{\circ} \mathrm{E}, 35^{\circ}-50^{\circ} \mathrm{N}\right), \mathbf{g}$ North America $\left(120^{\circ} \mathrm{W}-60^{\circ} \mathrm{W}\right.$, $\left.30^{\circ}-60^{\circ} \mathrm{N}\right)$, and $\mathbf{h}$ North Africa $\left(20^{\circ} \mathrm{W}-35^{\circ} \mathrm{E}, 15-30^{\circ} \mathrm{N}\right)$ in JJA. For $\mathbf{h}$, precipitation is averaged over the Sahel $\left(20^{\circ} \mathrm{W}-35^{\circ} \mathrm{E}, 10^{\circ}-20^{\circ} \mathrm{N}\right.$ : black box in Fig. 3d)

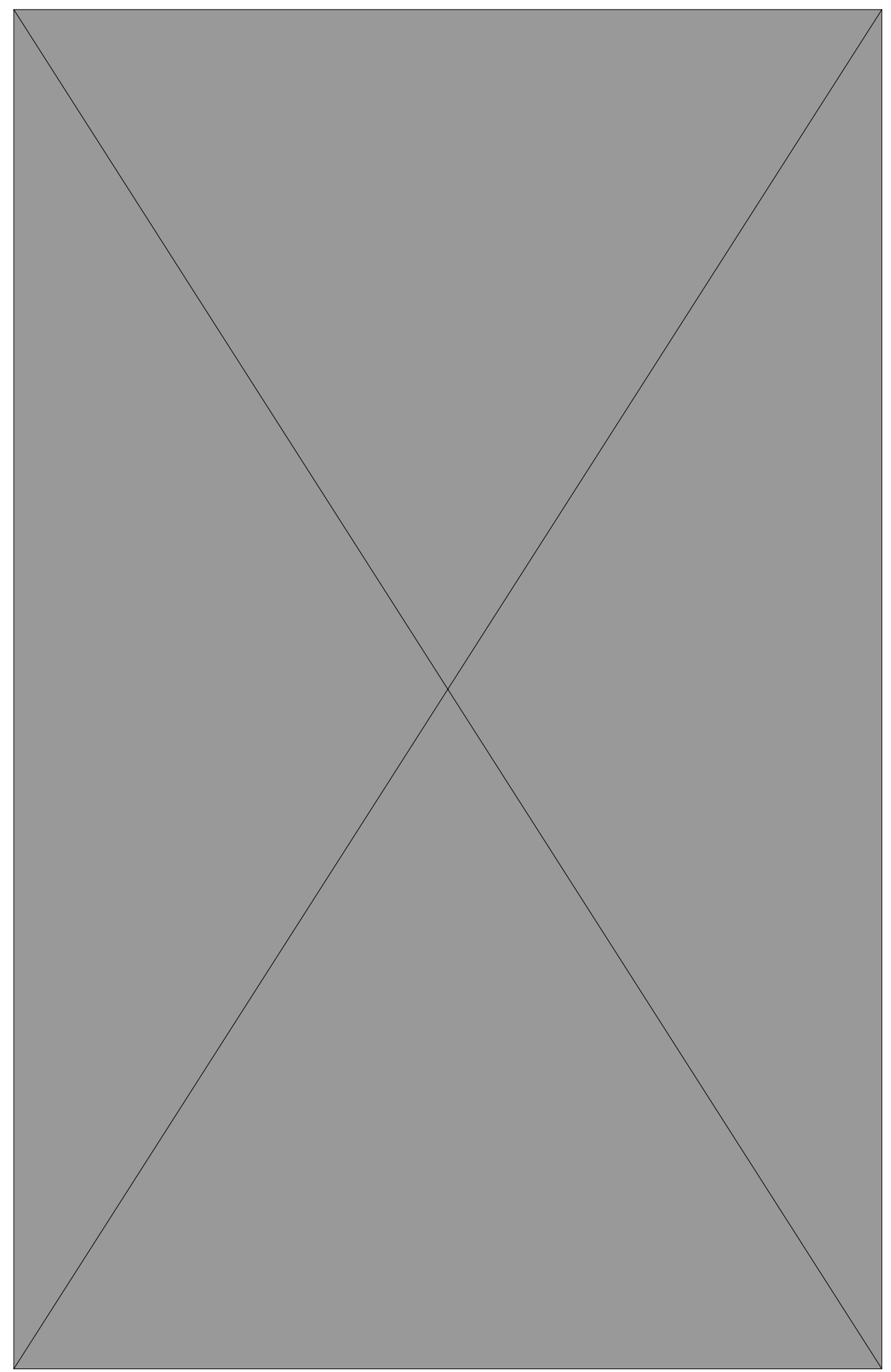


and South America. All these features are insensitive to the representation of air-sea interaction and they bear a similarity to observed anomalies (Fig. 3d and f) but are weaker in magnitude (Fig. 13g and $\mathrm{h}$ ). This suggests a robust role of anthropogenic forcing in 2012 anomalies in SAT, atmospheric circulation, and precipitation over the North Atlantic sector in boreal summer.

Over East Asia and adjacent oceans in boreal summer, some features of the observed circulation changes are captured in both the coupled and uncoupled simulations, while some other features are not (Fig. 11). Both simulations reproduce the observed anomalous anticyclonic circulation over the North Pacific, although they underestimate the magnitude. The circulation changes over the tropical western Pacific in uncoupled model simulations show opposite changes to those in observations and the coupled model show a weak anomalous cyclonic circulation (Fig. 11d-f). As a result, precipitation changes over East Asia are weak in the coupled model simulation (Fig. 11a), while in the uncoupled simulation there are significant increases (Fig. 11b). However, neither simulation reproduces the observed precipitation changes over East Asia (Fig. 11c), which suggests that either the model has a deficiency in response to anthropogenic forcing or the observed precipitation changes in 2012 over East Asia are possibly associated with internal variability (e.g., Zhou et al. 2013).

\section{Conclusions}

Several extreme anomalous climate conditions occurred in 2012 around the globe. In this paper, we take 2012 as an example to investigate the sensitivity of attribution conclusions to the impact of air-sea interaction. To isolate the role of air-sea coupling, we compared attribution conclusions derived from experiments with a coupled climate model, consisting of an atmospheric model coupled to a well resolved mixed-layer ocean with conclusions derived from parallel experiments with the same atmospheric model forced by daily SSTs taken from the coupled model experiments. The experimental design also allows us to compare simulated changes with observed changes. The main findings are summarized as follows:

- Model experiments indicate that changes in anthropogenic forcing (relative to the climate baseline period of 1964-1981) contributed significantly to 2012 seasonal SST anomalies in both boreal winter (JFM) and summer (JJA). Model experiments suggest about half of the magnitude of observed SST anomalies in 2012 over the Southern ocean, tropical Indian Ocean, tropical western Pacific, and subtropical North Atlantic can be associated with changes in anthropogenic forcing.
- The spatial patterns of changes in SAT in boreal summer in the coupled and uncoupled experiments are quantitatively similar. This suggests that the model responses in SAT to changes in anthropogenic forcing are not very sensitive to air-sea coupling. The model simulated SAT changes over various regions where observations showed extreme seasonal mean anomalies in 2012 are very close to observed changes, indicating an important role of changes in anthropogenic forcing for 2012 summer warming in these regions.

- The large scale changes in SAT over land in boreal winter, including in North and South America, Africa, Australia, and large area of Asian continent, are also similar in the coupled model and uncoupled model experiments. These similarities indicate a weak role of air-sea coupling in the model simulated response to changes in anthropogenic forcing in these regions. However, the SAT responses over mid-latitudes of the Northern Hemisphere, particularly over the eastern North America, Western Europe, and central and eastern Asia show some differences. Furthermore, neither the coupled nor uncoupled model reproduces the observed SAT anomalies over the Eurasian continent in JFM, suggesting that those anomalies are likely to have been induced by natural variability or that the model has a deficiency in response to anthropogenic forcing.

- Both coupled and uncoupled model experiments show some similar responses in the circulation in summer over the North Atlantic sector and increased precipitation over northern Europe in response to changes in anthropogenic forcing. Model experiments also consistently show reduced precipitation over North America and northern South America, and an increase over the Sahel, indicating a role for changes in anthropogenic forcing in driving summer precipitation in these regions. The similarity of the responses in the coupled and uncoupled models suggests a weak role of air-sea coupling. However, the magnitude of the simulated anomalies is much weaker than in observations. The weak responses of precipitation might, on the one hand, reflect a deficiency of the model's response to changes in anthropogenic forcing or an error in the changes in radiative forcing. On the other hand, they might suggest that a large portion of the changes in local precipitation in 2012 in observations might be due to internal variability.

- The attribution of regional circulation and precipitation changes in other regions shows a sensitivity to airsea coupling, in particular over the mid-high latitudes in the North Atlantic sector in boreal winter and in the summer monsoon region of East Asia. Over the North Atlantic sector both circulation and precipitation responses to anthropogenic forcing in 2012 boreal winter in the coupled experiments exhibit a similarity 
to the observed anomalies (although weaker in magnitude). The responses in the uncoupled experiments do not agree with the observed anomalies. However, the responses in neither experiment reproduce the spatial pattern and magnitude of observed precipitation anomalies in 2012 over East Asia in boreal summer, implying that either the model has a deficiency in its response to anthropogenic forcing, that missing forcing factors such as changes in sea ice extent were important, or that anomalous local precipitation in 2012 might have been predominantly induced by internal variability.

AGCMs forced by prescribed SSTs, with and without anthropogenic influences are widely used for attribution studies for particular climate events (e.g., Pall et al. 2011; Christidis et al. 2013, 2015; King et al. 2013; Rupp et al. 2013, 2017). This study demonstrates that attribution conclusions for surface SAT changes in boreal summer over the Northern Hemisphere may not be very sensitive to the representation of air-sea coupling. Good agreement between model experiments and observed anomalies also indicates the important role of changes in anthropogenic forcing for SAT anomalies in 2012. However, our results also suggest that a lack of explicit atmosphere-ocean coupling may lead to erroneous attribution conclusions for circulation and precipitation changes in some regions, particularly over the North Atlantic sector in boreal winter, and over East Asia in boreal summer, where atmospheric circulation changes are the dominant source of moisture transport for precipitation. This study highlights the importance of using ocean-atmosphere coupled models for attribution of regional circulation and precipitation anomalies in these regions. A caveat is that the changes we have studied were assessed relative to the baseline period of 1964-1981. The model response to external forcing might be sensitive to the baseline period mean state of atmosphere and therefore there is a need for further studies to assess this sensitivity. Additionally, the oceanic component of the model we used is a mixed-layer model, in which the ocean dynamic processes are not fully considered and changes in sea ice extent are not included. Therefore, it could be fruitful to perform similar experiments using fully coupled experiments to assess the robustness of our conclusions. Future directions might also include looking at other events [e.g., summer 2018 which experienced a number of extreme weather events in the Northern Hemisphere (Kornhuber et al. 2019)].

Acknowledgements This work was supported by EUPHEME project funded by the European Union through the ERA4CS ERA-NET. BD, RTS, LS, and LW are supported by the U.K. National Centre for Atmospheric Science-Climate (NCAS-Climate) at the University of Reading. The authors would like to thank two anonymous reviewers for their constructive comments on the early version of this paper.
Open Access This article is licensed under a Creative Commons Attribution 4.0 International License, which permits use, sharing, adaptation, distribution and reproduction in any medium or format, as long as you give appropriate credit to the original author(s) and the source, provide a link to the Creative Commons licence, and indicate if changes were made. The images or other third party material in this article are included in the article's Creative Commons licence, unless indicated otherwise in a credit line to the material. If material is not included in the article's Creative Commons licence and your intended use is not permitted by statutory regulation or exceeds the permitted use, you will need to obtain permission directly from the copyright holder. To view a copy of this licence, visit http://creativecommons.org/licenses/by/4.0/.

\section{References}

Adler RF, Huffman GF, Chang A, Ferraro R, Xie P, Janowiak J, Rudolf B, Schneider U, Curtis S, Bolvin D, Gruber A, Susskind J, Arkin P, Nelkin E (2003) The version 2 global precipitation climatology project (GPCP) monthly precipitation analysis (1979-present). J Hydrometeorol 4:1147-1167

Allan R, Ansell T (2006) A new globally complete monthly historical gridded mean sea level pressure dataset (HadSLP2): 1850-2004. J Clim 19:5816-5842

Barsugli JJ, Battisti DS (1998) The basic effects of atmosphereocean thermal coupling on midlatitude variability. J Atmos Sci $55: 477-493$

Bindoff NL, Stott PA, AchutaRao KM, Allen MR, Gillett N, Gutzler D, Hansingo K, Hegerl G, Hu Y, Jain S, Mokhov II, Overland J, Perlwitz J, Sebbari R, Zhang X, et al (2013) Detection and attribution of climate change: from global to regional. In: Stocker TF, Qin D, Plattner GK, Tignor M, Allen S K, Boschung J, Nauels A, Xia Y, Bex V, Midgley PM (eds) Climate change 2013: the physical science basis. In: Contribution of working group I to the fifth assessment report of the intergovernmental panel on climate change. Cambridge University Press, pp 867-952

Boé J, Terray L (2014) Land-sea contrast, soil-atmosphere and cloudtemperature interactions: interplays and roles in future summer European climate change. Clim Dyn 42:683-699

Blunden J, Arndt DS (2013) State of the climate in 2012. Bull Am Meteorol Soc 94:S1-S258. https://doi.org/10.1175/2013BAMSSt ateoftheClimate.1

Cheng L, Hoerling M, Smith L, Eischeid J (2018) Diagnosing humaninduced dynamic and thermodynamic drivers of extreme rainfall. J Clim 31:1029-1051

Cornforth RJ (2013) West African monsoon 2012. Weather 68:256-263

Christidis N, Stott PA, Scaife AA, Arribas A, Jones GS, Copsey D, Knight JR, Tennant WJ (2013) A new HadGEM3-A-based system for attribution of weather- and climate-related extreme events. J Clim 26:2756-2783

de Vries H, van Westrhenen R, van Oldenborgh GJ (2013) The February 2012 European cold spell that didn't bring the Dutch another 11-City Tour. Bull Am Meteorol Soc 94:S26-S28

Diffenbaugh NS, Scherer M (2013) Likelihood of July 2012 US temperatures in preindustrial and current forcing regimes. Bull Am Meteorol Soc 94:S6-S9

Dong BW, Gregory JM, Sutton RT (2009) Understanding land-sea warming contrast in response to increasing greenhouse gases. Part I: Transient adjustment. J Clim 22:3079-3097

Dong BW, Sutton RT, Shaffrey L (2017a) Understanding the rapid summer warming and changes in temperature extremes since the mid-1990s over Western Europe. Clim Dyn 48:1537-1554. https ://doi.org/10.1007/s00382-016-3158-8

Dong BW, Sutton RT, Shaffrey L, Klingaman NP (2017b) Attribution of forced decadal climate change in coupled and uncoupled 
ocean-atmosphere model experiments. J Clim. https://doi. org/10.1175/JCLI-D-16-0578.1

Dong BW, Sutton RT, Woollings TJ (2013) The Extreme European Summer 2012 (in explaining extreme events of 2012 from a climate perspective). Bull Am Meteorol Soc 94:S28-S32. https:// doi.org/10.1175/BAMS-D-13-00085.1

Fischer EM, Beyerle U, Schleussner CF, King AD, Knutti R (2018) Biased estimates of changes in climate extremes from prescribed SST simulations. Geophys Res Lett 45:8500-8509. https://doi. org/10.1029/2018GL079176

Folland C, Knight J, Linderholm H, Fereday D, Ineson S, Hurrell JW (2009) The summer North Atlantic Oscillation: past, present and future. J Clim 22:1082-1103. https://doi.org/10.1175/2008JCLI24 59.1

Fyfe JC, Boer GJ, Flato GM (1999) The Arctic and Antarctic Oscillations and their projected changes under global warming. Geophys Res Lett 26:1601-1604. https://doi.org/10.1029/1999GL900317

Harris I, Jones PD, Osborn TJ, Lister DH (2014) Updated high-resolution grids of monthly climatic observations-the CRU TS3.10 dataset. Int J Climatol 34:623-642. https://doi.org/10.1002/ joc. 3711

He J, Soden BJ (2016) Does the lack of coupling in SST-forced atmosphere-only models limit their usefulness for climate change studies? J Clim. https://doi.org/10.1175/JCLI-D-14-00597.1

Hendon HH, Lim E-P, Liu G (2012) The role of air-sea interaction for prediction of Australian summer monsoon rainfall. J Clim $25: 1278-1290$

Hirons LC, Klingaman NP, Woolnough SJ (2015) MetUM-GOML: a near-globally coupled atmosphere-ocean-mixed-layer model. Geosci Model Dev 8:363-379

Hirons LC, Klingaman NP, Woolnough SJ (2018) The impact of airsea interactions on the representation of tropical precipitation extremes. J Adv Model Earth Syst 10(2):550-559

Hoerling M, Eischeid J, Kumar A, Leung R, Mariotti A, Mo K, Schubert S, Seagar R (2013) Causes and predictability of the 2012 great plains drought. Bull Am Meteorol Soc 95:269-282. https:// doi.org/10.1175/BAMS-D-13-00055.1

Hu Y, Zhong Z, Liu X, Zhu Y (2012) Influence of air-sea interaction on the simulation of the East Asian summer monsoon: a case study. Dyn Atmos Oceans 53-54:1-16. https://doi.org/10.1016/j. dynatmoce.2011.12.001

Jones PD, Moberg A (2003) Hemispheric and large-scale air temperature variations: an extensive revision and update to 2001. J Clim 16:206-223

Kalnay E, Kanamitsu M, Kistler R, Collins W, Deaven D, Gandin L, Joseph D (1996) The NCEP/NCAR 40-year reanalysis project. Bull Am Meteor Soc 77:437-471

King AD, Lewis SC, Perkins SE, Alexander LV, Donat MG, Karoly DJ, Black MT (2013) Limited Evidence of Anthropogenic Influence on the 2011-12 Extreme Rainfall Over Southeast Australia, edited by T. C. Peterson, M. P. Hoerling, P. A. Stott, and S. C. Herring. Bull Am Meteorol Soc 94:S55-S58

Kornhuber K et al (2019) Extreme weather events in early summer 2018 connected by a recurrent hemispheric wave-7 pattern. Environ Res Lett 14:054002. https://doi.org/10.1088/1748-9326/ab13b $\mathrm{f}$

Lamarque JF et al (2010) Historical (1850-2000) gridded anthropogenic and biomass burning emissions of reactive gases and aerosols: methodology and application. Atmos Chem Phys 10(15):7017-7039. https://doi.org/10.5194/acp-10-7017-2010

Lamarque JF, Kyle G, Meinshausen M, Riahi K, Smith S, van Vuuren D, Conley A, Vitt F (2011) Global and regional evolution of shortlived radiatively-active gases and aerosols in the representative concentration pathways. Clim Change 109:191-212. https://doi. org/10.1007/s10584-011-0155-0
Large WG, McWilliams JC, Doney SC (1994) Oceanic vertical mixing - a review and a model with a nonlocal boundary-layer parameterization. Rev Geophys 32:363-403

Lin R, Zhu J, Zheng F (2016) Decadal shifts of East Asian summer monsoon in a climate model free of explicit GHGs and aerosols. Sci Rep 6:38546. https://doi.org/10.1038/srep38546

Marengo JA, Alves LM, Soares WR, Rodriguez DA, Camargo H, Riveros MP, Pabló AD (2013) Two contrasting severe seasonal extremes in tropical South America in 2012: flood in Amazonia and drought in northeast Brazil. J Climate 26:9137-9154

Martin ER, Thorncroft C, Booth BB (2014) The multidecadal Atlantic SST-Sahel rainfall teleconnection in CMIP5 simulations. J Clim 27:784-806

Mori M, Watanabe M, Shiogama H, Inoue J, Kimoto M (2014) Robust Arctic sea-ice influence on the frequent Eurasian cold winters in past decades. Nat Geosci. https://doi.org/10.1038/ngeo2277

National Academies of Sciences, Engineering, and Medicine (2016) Attribution of Extreme Weather Events in the Context of Climate Change. Washington, DC: The National Academies Press. https ://doi.org/10.17226/21852

Otto FEL (2017) Attribution of weather and climate events. Annu Rev Environ Resour 42:627-646. https://doi.org/10.1146/annurevenviron-102016-060847

Otto FEL, van der Wiel K, van Oldenborgh GJ, Philip S, Kew SA, Uhe P, Cullen H (2018) Climate change increases the probability of heavy rains in Northern England/Southern Scotland like those of storm Desmond - a real-time event attribution revisited. Environ Res Lett 13(2):024006

Pall P, Aina T, Stone DA, Stott PA, Nozawa T, Hilberts AGJ, Lohmann D, Allen MR (2011) Anthropogenic greenhouse gas contribution to flood risk in England and Wales in autumn 2000. Nature 470(7334):382-385. https://doi.org/10.1038/nature09762

Parker HR, Lott FC, Cornforth RJ, Mitchell DM, Sparrow S, Wallom D (2017) A comparison of model ensembles for attributing 2012 West African rainfall. Environ Res Lett 12:014019

Peterson TC, Hoerling MP, Stott PA, Herring SC (2013) Explaining extreme events of 2012 from a climate perspective. Bull Am Meteorol Soc 94:S1-S74

Rayner NA et al (2003) Global analyses of sea surface temperature, sea ice, and night marine air temperature since the late nineteenth century. J Geophys Res Atmos 108:4407. https://doi. org/10.1029/2002JD002670

Ringer MA, Martin GM, Greeves CZ, Hinton TJ et al (2006) The physical properties of the atmosphere in the new Hadley Centre Global Environmental Model (HadGEM1). Part II: aspects of variability and regional climate. J Clim 19:1302-1326

Risser MD, Stone DA, Paciorek CJ et al (2017) Quantifying the effect of interannual ocean variability on the attribution of extreme climate events to human influence. Clim Dyn 49:3051-3073

Rupp DE, Mote PW, Massey N, Otto FEL, Allen MR (2013) Human influence on the probability of low precipitation in the central United States in 2012. Bull Am Meteorol Soc 94:S2-S6. https:// doi.org/10.1175/BAMS-D-13-00085.1

Rupp DE, Li S, Mote PW, Massey N, Sparrow SN, Wallom DC (2017) Influence of the ocean and greenhouse gases on severe drought likelihood in the central US in 2012. J Clim 30:1789-1806

Sánchez-Benítez A, García-Herrera R, Barriopedro D, Sousa PM, Trigo RM (2018) The earliest European summer mega-heatwave of reanalysis period. Geophys Res Lett 45:1955-1962. https://doi. org/10.1002/2018GL077253

Sardeshmukh P, Hoskins BJ (1988) The generation of global rotational flow by steady idealized tropical divergence. J Atmos Sci 45:1228-1251

Scaife AA, Comer RE, Dunstone NJ, Knight JR, Smith DM, MacLachlan C, Martin N, Peterson KA, Rowlands D, Carroll EB, Belcher S, Slingo J (2017) Tropical rainfall, Rossby waves and regional 
winter climate predictions. Q J R Meteorol Soc 143:1-11. https ://doi.org/10.1002/qj.2910

Schneider U, Becker A, Finger P, Meyer-Christoffer A, Ziese M, Rudolf B (2014) GPCC's new land surface precipitation climatology based on quality-controlled in situ data and its role in quantifying the global water cycle. Theor Appl Climatol 115:15-40

Shepherd TG (2016) A common framework for approaches to extreme event attribution. Curr Clim Change Rep 2:28-38. https://doi. org/10.1007/s40641-016-0033-y

Shimizu MH, Cavalcanti IFA (2011) Variability patterns of Rossby wave source. Clim Dyn 37:441-454

Smith DM, Murphy JM (2007) An objective ocean temperature and salinity analysis using covariances from a global climate model. J Geophys Res 112:C02022. https://doi.org/10.1029/2005JC003172

Sperber KR et al (2013) The Asian summer monsoon: an intercomparison of CMIP5 vs. CMIP3 simulations of the late 20th century. Clim Dyn 41:2711-2744. https://doi.org/10.1007/s0038 2-012-1607-6

Stone DA, Risser MD, Angélil OM, Wehner MF, Cholia S, Keen N, Krishnan H, O'Brien TA, Collins WD (2018) A basis set for exploration of sensitivity to prescribed ocean conditions for estimating human contributions to extreme weather in CAM5.1-1degree. Weather Clim Extremes 19:10-19. https://doi. org/10.1016/j.wace.2017.12.003

Stott PA, Christidis N, Otto F, Sun Y, Vanderlinden J-P, van Oldenborgh G-J, Vautard R, von Storch H, Walton P, Yiou P, Zwiers FW (2016) Attribution of extreme weather and climate-related events. WIREs Clim Change 7:23-41

Trenberth KE, Fasullo JT, Shepherd TG (2015) Attribution of climate extreme events. Nat Clim Change 5:725-730. https://doi. org/10.1038/nclimate2657

Trigo RM et al (2013) The record winter drought of 2011-12 in the Iberian Peninsula. Bull Am Meteorol Soc 94:S41-S45

Uhe P, Otto FEL, Haustein K et al (2016) Comparison of methods: attributing the 2014 record European temperatures to human influences. Geophys Res Lett 43:8685-8693. https://doi. org/10.1002/2016gl069568

Valcke S, Caubel A, Declat D, Terray L (2003) OASIS3 Ocean Atmosphere Sea Ice Soil user's guide, Tech. Rep. TR/CMGC/03/69, CERFACS, Toulouse, France

Vautard R, Yiou P, Otto F et al (2016) Attribution of human-induced dynamical and thermodynamical contributions in extreme weather events. Environ Res Lett 11:114009. https://doi.org/10.1088/17489326/11/11/114009

Walters DN et al (2017) The Met Office unified model global atmosphere 6.0/6.1 and JULES global land 6.0/6.1 configurations. Geosci Model Dev 10:1487-1520. https://doi.org/10.5194/ gmd-2016-194
Wang B et al (2005) Fundamental challenge in simulation and prediction of summer monsoon rainfall. Geophys Res Lett 32:L15711. https://doi.org/10.1029/2005GL022734

Wang C, Zhang L, Lee S-K, Wu L, Mechoso CR (2014) A global perspective on CMIP5 climate model biases. Nat Clim Change 4:201-205. https://doi.org/10.1038/nclimate2118

Watson PA, Weisheimer A, Knight JR, Palmer T (2016) The role of the tropical west pacific in the extreme northern hemisphere winter of 2013/2014. J Geophysl Res Atmos 121:1698-1714. https://doi. org/10.1002/2015JD024048

WCRP (2013) WCRP grand challenges. https://www.wcrp-climate.org/ grandcha.shtml

Wilcox LJ, Yiou P, Hauser M, Lott FC, van Oldenborgh GJ, Colfescu I, Dong B, Hegerl G, Shaffrey L, Sutton R (2018) Multiple perspectives on the attribution of the extreme European summer of 2012 to climate change. Clim Dyn 50:3537-3555. https://doi. org/10.1007/s00382-017-3822-7

Wild M (2016) Decadal changes in radiative fluxes at land and ocean surfaces and their relevance for global warming. WIREs Clim Change 7:91-107

Willmott CJ, Matsuura K (2001) Terrestrial air temperature and precipitation: monthly and annual time series (1950-1999). https://clima te.geog.udel.edu/ climate/html_pages/README.ghcn_ts2.html

WMO (2014) The global atmosphere watch world data centre for greenhouse Gases. No 38. https://gaw.kishou.go.jp/static/publi cations/summary/sum38/sum38.pdf

Wood N, Staniforth A, White A, Allen T, Diamantakis M, Gross M, Melvin T, Smith C, Vosper S, Zerroukat M, Thuburn J (2014) An inherently mass-conserving semi-implicit semi-Lagrangian discretization of the deep-atmosphere global non-hydrostatic equations. Q J R Meteorol Soc 140:1505-1520. https://doi. org/10.1002/qj.2235

Yiou P, Cattiaux J (2013) Contribution of atmospheric circulation to wet north European summer precipitation of 2012. Bull Am Meteorol Soc 94:S39-S41

Yu B, Lin H (2016) Tropical atmospheric forcing of the wintertime North Atlantic oscillation. J Clim 29:1755-1772

Zhou T, Song F, Lin R, Chen X, Chen X (2013) The 2012 North China floods: Explaining an extreme rainfall event in the context of a long-term drying tendency. Bull Am Meteorol Soc 94:S49-S51

Zhu J, Shukla J (2013) The role of air-sea coupling in seasonal prediction of Asia-Pacific summer monsoon rainfall. J Clim 26:56895697. https://doi.org/10.1175/JCLI-D-13-00190.1

Publisher's Note Springer Nature remains neutral with regard to jurisdictional claims in published maps and institutional affiliations. 